\title{
Arching Effect and Displacement on Theoretical Estimation for Lateral Force Acting on Retaining Wall
}

\section{Jun-feng Jiang ( $\square$ 524973903@qq.com )}

Chengdu University of Technology https://orcid.org/0000-0002-2809-4884

\section{Qi-hua Zhao}

chengdu university of technology

\section{Shuairun Zhu}

chengdu university of technology

\section{Sheqin Peng}

chengdu university of technology

\section{Yonghong Wu}

Kunming University of Science and Technology

\section{Research Article}

Keywords: Retaining wall, Displacement, Arching effect, Numerical model and analysis, Intermediate state

Posted Date: February 22nd, 2021

DOI: https://doi.org/10.21203/rs.3.rs-161970/v1

License: (9) This work is licensed under a Creative Commons Attribution 4.0 International License. Read Full License 


\section{for lateral force acting on retaining wall}

$4 \quad{ }^{1}$ State Key Laboratory of Geo-hazard Prevention and Geo-environment Protection, Chengdu

5 University of Technology, 610059, Chengdu, Sichuan, P. R. China

$6{ }^{2}$ College of Architectural Engineer, Kunming University of Science and Technology, Kunming City,

7 650500, Kunming, Yunnan, P. R. China

$8 \quad *$ corresponding author: zhqh@163.com

9 Submitted on January 7, 2021 
A new approach is proposed to evaluate the non-limit active earth pressure in cohesive-frictional based on the horizontal slices method and limit equilibrium method. This approach takes into account the arching effect, displacement, average shear stress of the soil slice, rupture angle and tension cracks. The accuracy of the proposed method is demonstrated by comparing the experimental results and other theoretical methods. The comparison results show that the proposed approach is suitable for calculating the non-limit active earth pressure in cohesive-frictional soil and cohesionless soil. Additionally, the empirical formulations of the mobilized internal friction angle and soil-wall interface friction angle usually used to cohesionless soil are still applied to cohesive-frictional soil through comparison calculated results of other theoretical methods and finite element method. Some valid formulations of the rupture angle and tension cracks were derived considering the cohesion,

21 wall height, and unit weight.

Keywords: Retaining wall; Displacement; Arching effect; Numerical model and analysis;

23 Intermediate state

\section{Introduction}

An effective estimation of the lateral earth pressure is essential to the design of retaining walls for cohesive or cohesionless soil. The classical Coulomb (1776) theory or Rankine (1857) theory has been widely used as the simple model in practice. However, several laboratories and field results observed for retaining wall shown that the distribution of active earth pressure was nonlinear, and the

29 lateral earth pressure behind the field wall was mostly in the intermediate state (Tsagareli 1965;

30 Matsuo 1978; Bang 1985; Fang 1986; Zhou et al. 1990; Yue et al. 1992). Some scholars have 31 proposed substantially advanced procedures for predicting the nonlinear distribution of the lateral 
earth pressure in cohesionless soil (Handy 1985; Paik and Salgado 2003; Lu et al. 2012; Li et al. 2017; Chen et al. 2019). The research results showed that the soil arching led to the nonlinear distribution of active earth pressure (Fang, 1986).

In recent years, various research methods have been applied to calculate the displacement-dependent the lateral earth pressure and evaluate the working status of a retaining wall. These calculated methods of the lateral earth pressure considering the displacement mainly utilize a substitution method (Xu et al. 2013; Wang et al. 2015), and a linear model (Bang 1985; Golam et al. cracks.

\section{Mobilization of friction angle and cohesion}

The lateral earth pressure with the wall movement is gradually variation from an at-rest state to an 
active state (Bang 1985). The internal friction angle $\left(\varphi_{\mathrm{m}}\right)$, soil-wall interface friction angle $\left(\delta_{m}\right)$ and cohesion $\left(c_{m}\right)$ with displacement are gradually mobilized from an initial value to a peak value (Chang 1997). Bang (1985) believed that there is a linear relationship between the mobilized internal friction and displacement, so he first derived the formulation of the non-limit active earth pressure in cohesionless soil. Based on Bang' study, Chang (1997) and Wang et al. (2015) constructed an empirical distribution mode of mobilized internal friction when the horizontal displacement $(s)$ at the top of the wall exceeded the critical displacement $\left(s_{a}\right)$. In practice, the relationship is not linear between the mobilized internal friction and displacement (Liu 2014; Chen et al. 2019). Furthermore, the critical displacement $\left(s_{a}, s_{c}\right)$ of the critical internal friction angle and soil-wall interface friction angle are not consistent ( $\mathrm{Li}$ et al. 2017).

An empirical model about the mobilized friction angle $\left(\varphi_{m}, \delta_{m}\right)$, the initial friction angle $\left(\varphi_{0}, \delta_{0}\right)$ and the critical friction angle $(\varphi, \delta)$ can be obtained by Eq. (1) and Eq. (2) in cohesionless soil (Chang1997; Li et al. 2017).

$$
\begin{aligned}
& \varphi_{m}= \begin{cases}\varphi_{0}+\frac{4 \arctan \left(s / s_{\mathrm{a}}\right)}{\pi}\left(\varphi-\varphi_{0}\right) & \left(s \leq s_{\mathrm{a}}\right) \\
\varphi & \left(s \geq s_{\mathrm{a}}\right)\end{cases} \\
& \delta_{m}= \begin{cases}\delta_{0}+\frac{4 \arctan \left(s / s_{c}\right)}{\pi}\left(\delta-\delta_{0}\right) & \left(s s_{\mathrm{c}}\right) \\
\delta & \left(s \geq s_{\mathrm{c}}\right)\end{cases}
\end{aligned}
$$

where $s$ is the horizontal displacement of the wall at the arbitrary depth; $s_{a}$ is the critical displacement condition corresponding to the maximum internal friction angle; and $s_{c}$ is the critical displacement corresponding to the maximum soil-wall interface friction angle.

For normally consolidated soil, the internal friction angle $\left(\varphi_{0}\right)$ under the initial state can be obtained by Eq. (3) when the influence of the initial soil-wall interface friction angle is not considered. 


$$
\varphi_{0}=\arcsin \left(\frac{1-k_{0}}{1+k_{0}}\right)
$$

where $k_{0}$ is the coefficient of the at-rest earth pressure, which can be estimated by the empirical formulation (for example cohesive soil $k_{0}=0.95-\sin \varphi^{\prime}$, cohesionless soil $k_{0}=1-\sin \varphi^{\prime}$ and overconsolidated soil $k_{0}=1-\sin \varphi^{\prime}(O C R)^{\sin \varphi}$ ) (Mayne and Kulhawy 1983; Chen et al. 2019).

Although most scholars have studied the relationship between the mechanical parameters (cohesion and friction angle) and displacement of a retaining wall under translational motion (T mode), few have studies cohesive-frictional soil in this way. Xu et al (2013) derived a formulation for calculating the mobilized internal friction angle of cohesive-frictional soil with displacement through the stress of the Mohr's circle, which is quite different from some advised approaches for cohesionless soil; but his calculation method for mobilized soil-wall interface friction angle is based on prior achievements for cohesionless soil.

For the relationship between the mobilized cohesion $\left(c_{m}\right)$ and displacement, $\mathrm{Xu}$ et al. (2013) obtained the Eq. (5) by the geometric relationship in the stress of the Mohr's circle.

$$
c_{\mathrm{m}}=\frac{c \cdot \tan \varphi_{m}}{\tan \varphi}
$$

For further illustration, the mobilizations of the friction angle in cohesive-frictional soil are presented based on the numerical results. The empirical model and a laboratory model test are used to verify the effectiveness of the numerical results. The finite element model is composed of a $10 \mathrm{~m}$ high cantilever retaining wall and silty sand (Matsuo 1978). The boundary conditions are: the thickness of the mesh was $1 \mathrm{~m}$ to simulate the plane strain state; the total depth of the mesh and the width at the left side of retaining wall were two times the height of retaining wall. The top surface of the mesh is free, the bottom surfaces were fixed, and other sides can only rotate, as shown in Fig.1. The finite element mesh adopts a quadrilateral element. The element size is $0.5 \mathrm{~m}$. The material 
parameters are shown in Table 1 . The calculated results of the finite element method are shown in Table 2.

Resultant forces of the lateral earth pressure from the at-rest to intermediate active state were recorded with the wall movement. It was observed that resultant forces of the lateral earth pressure 101 decrease and remain at the same pace with the measured values in Fig 2. The shear force $(T)$ and lateral resultant force $(N)$ acting on retaining wall can be obtained by the finite element method. According to the shear force $T=N \tan \delta_{m}+(H-z) c_{w}$ in Fig.7 and the cohesion of soil-wall interface $c_{w}=c_{\mathrm{m}} \tan \delta_{m} / \tan \varphi_{\mathrm{m}}($ Spangler and Handy 1984; Zhu et al 2014), the mobilized soil-wall interface friction angle $\left(\delta_{m}\right)$ based on Rankine's theory can be obtained by Eq. (5).

$$
\delta_{\mathrm{m}}=\arctan \frac{T}{N+c H \cot \varphi-\frac{2(c \cdot \cot \varphi)^{2}}{\gamma \cot \varphi_{m} \tan \left(\frac{\pi}{4}-\frac{\varphi_{\mathrm{m}}}{2}\right)}}
$$

where $T$ and $N$ are the total vertical shear force and lateral resultant force in the finite element method, which acts on the back of retaining wall, respectively.

Fig. 3 shows that the mobilized soil-wall interface friction angle always keeps increasing with the

110 displacement until the soil is at the limit state. The initial value of the soil-wall interface friction 111 angle $\left(\delta_{0}\right)$ obtained by the finite element method is $3.28^{\circ}$, which is not consistent with half of the 112 limited internal friction angle in Fang's (1986) experiment. Various errors in the model experiment 113 may have caused certain deformation of the wall and soil, which make the experimental initial value 114 of the soil-wall interface friction angle larger than the ideal initial value. However, for Matsuo's 115 measured value, the soil-wall interface friction angle is too bigger than the theoretical value. After checking the Mohr's circle of stress for an arbitrary point near the retaining wall, this phenomenon is 117 impossible (Paik and Salgado 2003). Moreover, according to the measured value and calculated 
value by finite element method, the mobilized soil-wall interface friction angle is going to be smaller

119 than the limit internal friction angle $(\varphi)$, which is the same as what Fang (1986) and Li et al. (2017) observed in cohesionless soil. So the influence of the cohesion of the soil-wall interface on the soil-wall friction angle may be ignored in Matsuo's experiment, which causes the measured value of the soil-wall interface friction angle to be larger. By comparing the calculated values between the theoretical method and finite element method under different conditions, it can be seen that Eq. (2) is also applicable for cohesive-frictional soil. The initial soil-wall interface friction angle is advised to be $0^{\circ}$, and the critical displacement $\left(s_{c}\right)$ is approximately $0.01 \mathrm{H}$. expressed by Eq. (6).

$$
N=\frac{1}{2}\left(H-\frac{2 c_{\mathrm{m}}}{\gamma \sqrt{K_{a}}}\right)\left(\gamma H K_{a}-2 c_{m} \sqrt{K_{a}}\right)
$$
where $H$ is the total height of the retraining wall, and $\gamma$ is the unit weight of the soil.

The variation of the mobilized internal friction angle with the wall movement is presented in Fig. 4. Comparing the calculating values of the three methods, it shows that Eq. (1) is also applied to cohesive-frictional soil. The initial internal friction angle can be appropriately calculated by Eq. (3). The critical displacement $\left(s_{a}\right)$ is approximately $0.01 H$, which is agreement with $s_{c}$. It shows that the internal friction angle and soil-wall interface friction angle will reach the limit state at the same displacement. 


\section{Theoretical considerations}

140 The detailed derivation procedures for the non-limit active earth pressure in cohesive-frictional

\subsection{Coefficient estimation of non-limit active earth pressure}

Quinlan (1987) and Kingsley (1989) proved the shape of the soil arching is closer to the arc. According to Paik and Salgado's theory about soil arching, minor principal stress is always tangent to the arc, and major principal stress is always vertical to the arc tangent. As show in Fig. 5, the radius of the arc for the minor principal stress is $r$, and the centre of arc is the point $O$. The depth of tension cracks is $z$. The length of the trapezoidal layer element is $L$. The distance between the trapezoidal layer element and the top of the wall is $y$. The deflection angle between the major principal stress and the horizontal surface is $\theta_{A}$ at point $\mathrm{A}$. For point $\mathrm{B}$, the deflection angle between the major principal stress and the horizontal surface is $\theta_{B}$. For the arbitrary point $D$, the deflection angle between the major principal stress and the horizontal surface is $\theta$.

To simplify the following theoretical derivation, the stress state will be analyzed by the translational coordinate system in Fig. 6. The transition formulation of the old stress and the new 
stress is as follows in Eq. (8).

$$
\left\{\begin{array}{l}
\sigma^{\prime}=\sigma+\sigma_{0} \\
\tau^{\prime}=\tau
\end{array}\right.
$$

where $\sigma$ and $\tau$ are the normal stress and shear stress in the old coordinate system $(\tau \mathrm{O} \sigma), \sigma^{\prime}$ and $\tau^{\prime}$ is the normal stress and shear stress in the new coordinate system $\left(\tau^{\prime} \mathrm{O} \sigma^{\prime}\right)$, respectively.

According to the Mohr's circle representation of stresses and stress analysis in Fig. 6, the normal stress $\left(\sigma_{w}\right)$ and shear stress $\left(\tau_{w}\right)$ acting on retaining wall at point $A$ can be expressed by Eq.(9) (Tu et al. 2012; Lou 2015).

$$
\left\{\begin{array}{l}
\sigma^{\prime}{ }_{w}=\sigma_{1}^{\prime} \cos ^{2} \alpha+\sigma_{3}^{\prime} \sin ^{2} \alpha \\
\tau^{\prime}{ }_{w}=\left(\sigma_{1}^{\prime}-\sigma_{3}^{\prime}\right) \sin \alpha \cos \alpha
\end{array}\right.
$$

where $\sigma_{1}{ }^{\prime}$ and $\sigma_{3}{ }^{\prime}$ are the major principal stress and minor principal stress in the new coordinate system, respectively; $\alpha$ is the angle between the direction of the major principle stress and the vertical direction of the retaining wall. According to the equation $\tau^{\prime}{ }_{\mathrm{w}}={\sigma^{\prime}}_{\mathrm{w}} \tan \delta_{m}, \alpha$ can be obtained from the following relationship with the soil-wall interface friction angle.

$$
\alpha=\frac{1}{2} \arccos \frac{-\left(1+K_{a}\right) \tan ^{2} \delta_{m}-\sqrt{\left(1-K_{a}\right)^{2}-4 K_{a} \tan ^{2} \delta_{m}}}{\left(1-K_{a}\right)\left(\tan ^{2} \delta_{m}+1\right)}
$$

Then the horizontal stress $\left(\sigma_{A h}{ }^{\prime}\right)$ at point A can be obtained by Eq. (11).

$$
\sigma_{\mathrm{Ah}}^{\prime}=\left(\sigma_{1}^{\prime} \cos ^{2} \alpha+\sigma_{3}^{\prime} \sin ^{2} \alpha\right) \cos \varepsilon
$$

where $\varepsilon$ is the rotation angle of the wall.

Similarly, according to the stress analysis in Figure $6(c)$, the normal stress $\left(\sigma_{s}{ }^{\prime}\right)$ and shear stress $178\left(\tau_{s}{ }^{\prime}\right)$ acting on retaining wall at point $B$ can be expressed by Eq. (12).

$$
\left\{\begin{array}{l}
\sigma_{\mathrm{s}}^{\prime}=\sigma_{1}^{\prime} \sin ^{2}\left(\frac{\pi}{4}-\frac{\varphi_{m}}{2}\right)+\sigma_{3}^{\prime} \cos ^{2}\left(\frac{\pi}{4}-\frac{\varphi_{m}}{2}\right) \\
\tau_{\mathrm{s}}^{\prime}=\left(\sigma_{1}^{\prime}-\sigma_{3}^{\prime}\right) \sin \left(\frac{\pi}{4}-\frac{\varphi_{m}}{2}\right) \cos \left(\frac{\pi}{4}-\frac{\varphi_{m}}{2}\right)
\end{array}\right.
$$

According to the Mohr's circle representation of the stresses in Figure 6(a), the horizontal normal 
stress $\left(\sigma_{v}{ }^{\prime}\right)$ is related to the vertical normal stress $\left(\sigma_{h}{ }^{\prime}\right)$ by Eq. (13). Then the relationship can also be applied to an arbitrary point $\mathrm{D}$ in the $A B$ trapezoidal layer element.

$$
\sigma_{1}^{\prime}-\sigma_{\mathrm{v}}^{\prime}=\sigma_{\mathrm{h}}^{\prime}-\sigma_{3}^{\prime}
$$

Although the direction of the principal stress deflects after the arching effect appears, the horizontal stress of the arbitrary position is nearly equal in the $A B$ trapezoidal layer element of the sliding wedge. This is different from the vertical stress (Chen et al, 2019).

Similarly, the horizontal normal stress, the vertical normal stress and the shear stress at an arbitrary point $D$ of the trapezoidal layer element can be obtained from the following relationship:

$$
\left\{\begin{array}{l}
\sigma_{D \mathrm{~h}}^{\prime}=\sigma_{1}^{\prime} \cos ^{2} \theta+\sigma_{3}{ }_{3} \sin ^{2} \theta \\
\sigma_{{ }^{\prime}}^{\prime}=\sigma_{1}^{\prime} \sin ^{2} \theta+\sigma^{\prime}{ }_{3} \cos ^{2} \theta \\
\tau_{D}^{\prime}=\left(\sigma_{1}^{\prime}-\sigma_{3}^{\prime}\right) \sin \theta \cos \theta
\end{array}\right.
$$

In Fig. 5, the average vertical stress $\left(\sigma_{a v^{\prime}}\right)$ in the $\mathrm{AB}$ trapezoidal layer element can be derived from the total vertical stress divided by the width $(L)$ (Rao et al. 2016).

where the radius of the arc can be solved by Eq. (16), and the deflection angle of the stress $\left(\theta_{A}, \theta_{B}\right)$ can be obtained by Eq. (17).

$$
\begin{gathered}
\sigma_{a v}^{\prime}=\frac{\int_{L} \sigma_{D v}^{\prime} \mathrm{d} L}{L}=\frac{\int_{\theta_{A}}^{\theta_{B}} \sigma_{D_{\nu}}^{\prime} r \sin \theta d \theta}{L}=\frac{\int_{\theta_{A}}^{\theta_{B}}\left(\sigma_{1}^{\prime} \sin ^{2} \theta+\sigma_{3}^{\prime} \cos ^{2} \theta\right) r \sin \theta d \theta}{L} \\
=\sigma_{1}^{\prime}+\frac{\cos ^{3} \theta_{A}-\cos ^{3} \theta_{B}}{3\left(\cos \theta_{A}-\cos \theta_{B}\right)}\left(\sigma_{3}^{\prime}-\sigma_{1}^{\prime}\right)
\end{gathered}
$$

where $\beta$ is the angle between the potential slip surface and horizontal surface.

199 The coefficient of the non-limit active earth pressure $\left(K_{a w}\right)$ is defined as the ratio of the horizontal 
(Handy, 1985; Zhu, 2014). Thus, $K_{a w}$ can be derived from Eq. (18).

$$
K_{\mathrm{aw}}=\frac{\sigma_{\mathrm{Ah}}}{\sigma_{\mathrm{av}}}=\frac{\sigma_{\mathrm{Ah}}^{\prime}-\sigma_{0}}{\sigma_{a v}^{\prime}-\sigma_{0}}=\frac{\sigma_{1}^{\prime}\left(\cos ^{2} \alpha+K_{\mathrm{a}} \sin ^{2} \alpha\right) \cos \varepsilon-c_{\mathrm{m}} \cot \varphi_{m}}{\sigma_{1}^{\prime}\left[1+\frac{\left(K_{\mathrm{a}}-1\right)\left(\cos ^{3} \theta_{A}-\cos ^{3} \theta_{B}\right)}{3\left(\cos \theta_{A}-\cos \theta_{B}\right)}\right]-c_{\mathrm{m}} \cot \varphi_{m}}
$$

When a point in cohesionless soil reaches the limit state, the relationship between the major principal stress and the minor principal stress is given as follows (Rao et al. 2016; Chen et al. 2019).

$$
K_{\mathrm{a}}=\frac{\sigma_{3}^{\prime}}{\sigma_{1}^{\prime}}=\frac{1-\sin \varphi_{m}}{1+\sin \varphi_{m}}
$$

The major principal stress $\left(\sigma_{1}^{\prime}\right)$ in cohesive-frictional soil can be obtained by Eq. (20).

$$
\sigma_{1}^{\prime}=\sigma_{1}+\sigma_{0}=\gamma y+c_{\mathrm{m}} \cot \varphi_{\mathrm{m}}
$$

As shown in the above formulation, $K_{a w}$ is related to the change with the depth, and it will cause difficulties when solving the differential equation later. However, when the wall is in the initial position, the effect of soil arching should not appear yet, and the coefficient of the non-limit active earth pressure $\left(K_{a w}\right)$ should keep pace with the coefficient of the at-rest earth pressure $\left(K_{0}\right)$. In reality, $K_{a w}$ is inconsistent with the actual initial situation in Eq. (18), and it still continues to increase with the increasing depth in cohesive-frictional soil. In addition, there are generally tension cracks in cohesive-frictional soil on the top of retaining wall. When $\mathrm{y} \geq \mathrm{z}$ and $\varepsilon=0$, the coefficient of the non-limit active earth pressure $\left(K_{a w}\right)$ is equal at the arbitrary depths after the displacement is determined. If $\mathrm{y}=H$, it can be substituted into Eq. (18), and it can be regarded the value as the initial coefficient $\left(K_{o}\right)$ of every point along the depth. Then, the coefficient of the average non-limit active earth pressure $\left(K_{a w n}\right)$ of every point along the depth shows the same change as the wall movement.

$$
K_{\text {awn }}=\frac{\sigma_{\mathrm{Ah}}}{\sigma_{\mathrm{av}}}=\frac{\sigma^{\prime}{ }_{\mathrm{Ah}}-\sigma_{0}}{\sigma_{a v}^{\prime}-\sigma_{0}}=\frac{\left(\cos ^{2} \alpha+K_{\mathrm{a}} \sin ^{2} \alpha\right) \cos \varepsilon-\frac{c_{\mathrm{m}} \cot \varphi_{m}}{\gamma H+c_{\mathrm{m}} \cot \varphi_{m}}}{1+\frac{\left(K_{\mathrm{a}}-1\right)\left(\cos ^{3} \theta_{A}-\cos ^{3} \theta_{B}\right)}{3\left(\cos \theta_{A}-\cos \theta_{B}\right)}-\frac{c_{\mathrm{m}} \cot \varphi_{m}}{\gamma H+c_{\mathrm{m}} \cot \varphi_{m}}}
$$


The horizontal slices method has been widely used for determining active earth pressure at the intermediate state (Ahmadabadi et al. 2009; Chen et al. 2019), but the horizontal shear stress of the trapezoidal layer element is hardly considered. Actually, if the horizontal displacement of each point on the retaining wall is inconsistent, there must be a mutual dislocation among the soil slices. On the other hand, the horizontal shear stress of each point in the trapezoidal layer element is not equal

\subsection{Tension cracks and rupture angle in cohesive-frictional soil}

Because the depth of tension cracks at the top of retaining wall is not only related to the mechanical parameters of the soil, but it is also related to the mechanical parameters of the soil-wall interface. Moreover, tension cracks at the top of retaining wall are more likely to occur at contact position of the wall and soil in engineering practice. The cohesion $\left(c_{m}\right)$ of the soil should be replaced by cohesion of soil-wall interface $\left(c_{w}\right)$ in practical engineering application in Eq. (26). According to the boundary conditions: $y=z,\left.\quad P_{\mathrm{am}}\right|_{y=z}=0$ and $K_{\text {aw }}=0$, substitute the conditions into Eq. (18), the depth

(z) of tension cracks considering the arching effect can be calculated by Eq. (26). 


$$
z=\frac{c_{w}\left[1-\cos \varepsilon\left(\cos ^{2} \alpha+K_{a} \sin ^{2} \alpha\right)\right]}{\gamma \tan \varphi_{\mathrm{m}} \cos \varepsilon\left(\cos ^{2} \alpha+K_{\mathrm{a}} \sin ^{2} \alpha\right)}
$$

If the mechanical parameters of the soil were already known, the calculated values for tension cracks could be compared with different theoretical methods in Fig. 8. Because Rankine's theory considered the influence of the soil cohesion $\left(c_{m}\right)$, Lou (2015) ignored the influence of the rotation angle $(\varepsilon)$, while the proposed method considered the smaller cohesion of the soil-wall interface $\left(c_{w}\right)$, the calculated values of the proposed method is smaller than other two approaches. Moreover, the depth of tensile cracks for Rankine and Lou's theory was about $1.9 \mathrm{~m}$ in the initial state, but it should be closer to $0 \mathrm{~m}$ in the practical initial situation. Therefore, the proposed method is more applicable for calculating the depth of tensile cracks under intermediate displacement. theory. Based on this assumption, some scholars researched the nonlinear distribution of active earth pressure (Paik and Salgado 2003; Tu and Jia 2012). Kuamr (2010) derived a formulation for the rupture angle considering tension cracks, cohesion and seismic load, but tension cracks are still obtained by the simple Rankine theory. Rao et al. (2016) also derived the calculated formulation for the rupture angle by the geometrical relationship with soil arching. To obtain a simple formulation for the angle of the potential slip surface $(\beta)$ in cohesive-frictional soil, the proposed method still need to be assumed that the total weight of the slip zone (ABC) always remains constant from the initiation to failure.

In Fig.7, $T_{1}$ and $T_{2}$ are the shear forces in the $\mathrm{BC}$ and $\mathrm{AB}$ plane, $N_{1}$ and $N_{2}$ are both the normal forces across the contact surface $\mathrm{BC}$ and $\mathrm{EB}$, respectively; $Q$ and $R$ are both the resultant forces acting on the sliding wedge. 
Based on the Mohr-Coulomb criterion, the shear forces $\left(T_{1}, T_{2}\right)$ can be obtained by Eq. (27).

$$
\left\{\begin{array}{l}
T_{1}=N_{1} \tan \varphi_{m}+\frac{c_{\mathrm{m}}(H-\mathrm{z})}{\sin \beta} \\
T_{2}=N_{2} \tan \delta_{m}
\end{array}\right.
$$

The normal force $\left(N_{1}, N_{2}\right)$ along the contact surface can be expressed by Eq. (28).

$$
\left\{\begin{array}{l}
N_{1}=\frac{G \cos \psi \cos \left(\varepsilon+\delta_{\mathrm{m}}\right)}{\cos \left(\beta-\psi-\varepsilon-\delta_{\mathrm{m}}\right)} \\
N_{2}=Q \cos \delta_{m}
\end{array}\right.
$$

The total weight $(G)$ of the soil wedge $(E B C D)$ can be obtained by Eq. (29).

$$
G=\frac{1}{2} \gamma H^{2}(\cot \beta+\tan \varepsilon)-\frac{\gamma^{2}}{2} \cot \beta
$$

By Substituting Eq. (27), Eq. (28) and Eq. (29) into Eq. (26), resultant force of the lateral earth pressure $(Q)$ can be derived from Eq. (30).

$$
Q=\frac{1}{2} \lambda_{1} \gamma H^{2}(\cot \beta+\tan \varepsilon)-\frac{\lambda_{1} \gamma Z^{2}}{2} \cot \beta-\lambda_{2} c
$$

where $\lambda_{1}$ and $\lambda_{2}$ are the coefficients obtained by Eq. (31).

$$
\left\{\begin{array}{l}
\lambda_{1}=\frac{\sin \left(\beta-\varphi_{\mathrm{m}}\right) \cos \psi}{\cos \left(\beta-\psi-\varepsilon-\delta_{\mathrm{m}}\right) \cos \varphi_{\mathrm{m}}} \\
\lambda_{2}=\frac{H-z}{\tan \beta \cos \left(\varepsilon+\delta_{\mathrm{m}}\right)}
\end{array}\right.
$$

Because there is no cohesion in cohesionless soil, the angle between the reaction force $(R)$ and normal $\mathrm{BC}$ plane is equal to the internal friction angle $\left(\varphi_{m}\right)$. However, some scholars still ignored the influence of cohesion on the reaction force, when the soil is viscous (Xu et al 2013; Zhu et al. 2015). Actually, the relationship between the angle $(\psi)$ and other factors is intricate in cohesive-frictional soil. Based on the equivalence principle of the shear strength (Zhao and Bai, 2004), the angle ( $\psi$ ) of the reaction force $R$, internal soil friction $(\varphi)$ and cohesion $(c)$ can be established using the following relationship for Eq. (32).

$$
N_{\mathrm{1}} \tan \psi=N_{\mathrm{1}} \tan \varphi_{\mathrm{m}}+\frac{c_{m}(H-\mathrm{z})}{\sin \beta}
$$


By Substituting Eq. (28) and Eq. (29) into Eq. (32), the following Eq. (33) can be obtained.

$$
\tan \psi=\frac{\gamma(H+z) \cdot \tan \varphi_{\mathrm{m}}+2 c_{\mathrm{m}}\left[1+\tan \beta \cdot \tan \left(\delta_{\mathrm{m}}+\varepsilon\right)\right]}{\gamma(H+z)-2 c_{\mathrm{m}}\left[\tan \beta-\tan \left(\delta_{\mathrm{m}}+\varepsilon\right)\right]}
$$

If the soil-wall interface is upright and smooth, the failure plane $(\beta)$ is $45^{\circ}+\varphi / 2$, and this condition

can be substituted into Eq.(33); therefore, the angle $(\psi)$ of the reaction force $R$ will become a known

parameter taking into account the influence of the cohesion by Eq. (34).

$$
\tan \psi=\tan \varphi_{\mathrm{m}}+\frac{2 c_{m}\left[1+\tan \left(\frac{\pi}{4}+\frac{\varphi_{\mathrm{m}}}{2}\right)\right]}{\gamma H}
$$

According to Eq. (30), $Q$ is a function about $\beta$. The depth (z) of tension cracks is also a function

about $\beta$, but it is not related to the wall height. It is difficult to obtain a formulation about $\beta$ by directly differentiating $\beta$ from Eq. (30). However, if by substituting $H=y$ (depth) to Eq. (30), active earth pressure $\left(p_{a}\right)$ can firstly be obtained through $p_{a}=\frac{\partial Q}{\partial \mathrm{y}}$.

$$
p_{a}=\frac{\partial Q}{\partial \mathrm{y}}=\lambda_{1} \gamma y(\tan \varepsilon+\cot \beta)-\frac{c_{m} \cot \beta}{\cos \left(\varepsilon+\delta_{\mathrm{m}}\right)}
$$

Because the failure plane always passes through point $B$, the rupture angle $(\beta)$ is related to the wall height $(H)$ instead of the depth $(y)$. Substitute Eq. (31) and $h=H$ into Eq. (35); then active earth pressure $\left(p_{a}\right)$ is a function about $\cot \beta$.

Because $\cot \beta$ is monotonic functions about $\beta$, if only one value exists for $\cot \beta$ which can make $p_{a}$ reach the extreme value, it is obvious that only an existed value for $\beta$ can make $p_{a}$ reach an extreme value. Since $\beta$ satisfies the conditions: $0^{\circ}<\beta<90^{\circ}, \cot \beta$ cannot be negative (Kumar 2010). When

$\frac{\partial p_{a}}{\partial(\cot \beta)}=0$, only a limit value can be obtained for $\cot \beta$ by Eq. (36).

$$
\cot \beta=-\tan \left(\psi+\varepsilon+\delta_{\mathrm{m}}\right)+\sqrt{\frac{H \gamma\left[\tan \left(\psi+\varepsilon+\delta_{n}\right)-\tan \varepsilon\right]\left[\tan \left(\psi+\varepsilon+\delta_{n}\right) \tan \varphi_{\mathrm{m}}+1\right]}{H \gamma \tan \varphi_{\mathrm{m}}-c_{m} \cdot \tan \psi \tan \left(\delta_{n}+\varepsilon\right)+c_{m}}}
$$

When $c=0$ and $\psi=\varphi_{\mathrm{m}}$, Eq. (37) is the Coulomb solution of rupture angle by substituting them into Eq. (36) (Gong, 2014). 


$$
\cot \beta=-\tan \left(\varphi_{\mathrm{m}}+\varepsilon+\delta_{\mathrm{m}}\right)+\sqrt{\left[\tan \left(\varphi_{n}+\varepsilon+\delta_{m}\right)-\tan \varepsilon\right]\left[\tan \left(\varphi_{n}+\varepsilon+\delta_{m}\right)+\cot \varphi_{\mathrm{m}}\right]}
$$

In Fig. 9, several theoretical methods for determining the rupture angle were compared. The results show that the potential rupture angle $(\beta)$ continues to increase with displacement increase from a potential slip surface to the critical failure surface except for Rao's method, calculated values of the proposed method is consistent with Rankine solution and Zhu's method. When the shear strength of the soil will reach the limit state, the rupture angle for proposed method will gradually approach $45^{\circ}+\varphi / 2$. Because Rao et al. (2015) derived a formulation of rupture angle based on the

312 geometrical relationship with arching effect, but other methods obtained the formulation of rupture angle based on the limit equilibrium method, the calculated values of Rao's method were

significantly larger than other methods. Moreover, the proposed method and Zhu's method considered the influence of the wall height, cohesion and unit weight; but other methods only considered the internal friction angle and the soil-wall friction angle.

\subsection{Lateral earth pressure at the intermediate active state}

To obtain active earth pressure at the intermediate state, a trapezoidal layer element is subjected to mechanical analysis, as shown in Fig. 10. al. 2019).

$$
\tau_{w} d y \tan \varepsilon-\sigma_{\mathrm{w}} d y+\sigma_{\mathrm{s}} d y-\tau_{\mathrm{s}} d y \cot \beta+\tau_{\mathrm{am}} L-\left(\tau_{\mathrm{am}}+d \tau_{\mathrm{am}}\right)[L-d y(\tan \varepsilon+\cot \beta)]=0
$$

where the length $(L)$ of the trapezoidal layer element can be expressed by the formulation $L=(H-y)(\tan \varepsilon+\cot \beta)$.

According to the above assumptions, the stresses in the soil have the following relationships.

$$
\tau_{w}=\sigma_{\mathrm{w}} \tan \delta_{m} ; \tau_{\mathrm{s}}=\sigma_{\mathrm{s}} \tan \varphi_{m}+c_{m} ; \sigma_{\mathrm{Ah}}=K_{a w n} \sigma_{\mathrm{av}}
$$


From Eq. (9) and Eq. (11), the following equation can be obtained:

$$
\sigma_{\mathrm{w}}=\frac{K_{a w n} \sigma_{a v}}{\cos \varepsilon}+\sigma_{0}\left(\frac{1}{\cos \varepsilon}-1\right)
$$

Based on Eq. (24), the average shear stress of the trapezoidal layer element $\left(\tau_{a m}\right)$ can be expressed as the following Eq. (41) by the average vertical stress $\left(\sigma_{a v}\right)$.

$$
\tau_{\mathrm{am}}=K \sigma_{\mathrm{av}}
$$

Eq. (39), Eq. (40) and Eq. (41) are substituted into Eq. (38). Considering that the second derivative and rotation angle $(\varepsilon)$ are generally sufficiently small, their influence can be ignored to simplify the formulation. Therefore, Eq. (42) can be derived as follows:

$$
\sigma_{\mathrm{s}}=\frac{K^{\prime} L d_{\sigma_{a v}}}{\left(1-\tan \varphi_{m} \cot \beta\right) d y}+\frac{\sigma_{a v}\left(K_{a v n}-K^{\prime} \cot \beta\right)-K^{\prime} \cot \beta \sigma_{0}+c_{m} \cot \beta}{1-\tan \varphi_{m} \cot \beta}
$$

For the trapezoidal layer element in Fig. 10, the static equilibrium in the vertical direction requires the use of Eq. (43):

$$
\sigma_{\mathrm{av}} L+d G-\left(\sigma_{\mathrm{av}}+d \sigma_{a v}\right)[L-d y(\tan \varepsilon+\cot \beta)]-\sigma_{\mathrm{w}} d y \tan \varepsilon-\tau_{w} d y-\sigma_{\mathrm{s}} d y \cot \beta-\tau_{s} d y=0
$$

The above formulation is simplified; The following Eq. (44) can be obtained.

$$
\frac{d \sigma_{\mathrm{av}}}{d y}=\gamma+\frac{\sigma_{\mathrm{av}}}{H-y}-\frac{\sigma_{w}\left(\tan \delta_{m}+\tan \varepsilon\right)+\sigma_{s}\left(\cot \beta+\tan \varphi_{m}\right)+c_{m}}{L}
$$

Eq. (40) and Eq. (42) are substituted into Eq. (44), and Eq. (45) is derived as follows:

$$
A \frac{d \sigma_{\mathrm{av}}}{d y}=\gamma+B \frac{\sigma_{\mathrm{av}}}{H-y}-\frac{C}{H-\mathrm{y}}
$$

where $A, B$ and $C$ are the constants, and they yield the following expressions:

$$
\left\{\begin{array}{l}
A=1+\frac{K^{\prime}}{\tan \left(\beta-\varphi_{m}\right)} \\
B=1-\frac{K_{\text {awn }}\left(\tan \delta_{m}+\tan \varepsilon\right)}{\cos \varepsilon(\cot \beta+\tan \varepsilon)}-\frac{K_{a w n}-K^{\prime} \cot \beta}{\tan \left(\beta-\varphi_{m}\right)(\cot \beta+\tan \varepsilon)} \\
C=\frac{\sigma_{0}\left(\tan \delta_{m}+\tan \varepsilon\right)(1-\cos \varepsilon)}{\cos \varepsilon(\cot \beta+\tan \varepsilon)}+\frac{c_{m}-K^{\prime} \sigma_{0}}{\tan \left(\beta-\varphi_{m}\right)(1+\tan \beta \tan \varepsilon)}+\frac{c_{m}}{\cot \beta+\tan \varepsilon}
\end{array}\right.
$$

Because the boundary condition is the average vertical stress $\sigma_{a v}=\gamma z$, when $y=\mathrm{z}$. Substituting them 
into equation (45), the average vertical stress can be expressed by Eq. (46).

$$
\sigma_{\mathrm{av}}=\left[\gamma+\frac{\gamma(H-z)}{A+B}-\frac{C}{B}\right]\left(\frac{H-y}{H-\mathrm{z}}\right)^{-\frac{B}{A}}-\frac{\gamma(H-y)}{A+B}+\frac{C}{B}
$$

When $0 \leq y<z$, the horizontal stress $\sigma_{h}=0$ because of tension cracks; when $\mathrm{z} \leq y<\boldsymbol{H}$, the

horizontal stress $\sigma_{\mathrm{h}}=K_{a w} \sigma_{\mathrm{av}}$.

$$
\sigma_{\mathrm{h}}= \begin{cases}0 & K_{\text {awn }}\left\{\left[\gamma+\frac{\gamma(H-z)}{A+B}-\frac{C}{B}\right]\left(\frac{H-y}{H-z}\right)^{\frac{-B}{A}}-\frac{\gamma(H-y)}{A+B}+\frac{C}{B}\right\} \begin{array}{l}
(0 \leq y<z) \\
(z \leq y<H)
\end{array}\end{cases}
$$

In Fig.7, the angle between active earth pressure and the horizontal surface is $\delta_{m}+\varepsilon$ (Zhao and Bai 2004).Therefore, the non-limit active earth pressure $\left(p_{a m}\right)$ is derived from Eq. (48).

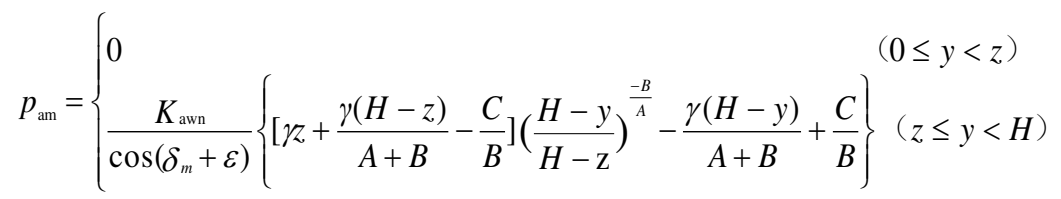

According to Eq. (48), the non-limit active earth pressure $\left(p_{a m}\right)$ with the displacement increases is

possibly negative on the bottom of the wall as the displacement increases because of soil arching.

Therefore, this part of the negative earth pressure should be ignored. Assuming that $y_{0}$ is a critical

point of the lateral earth pressure from the bottom of the wall, the non-limit lateral resultant force

$\left(Q_{m}\right)$ is given as follows:

$$
Q_{\mathrm{m}}=\int_{z}^{H-y_{0}} p_{a \mathrm{~m}} \mathrm{~d} y=\frac{K_{\text {avn }}}{\cos \left(\delta_{m}+\varepsilon\right)}\left\{\left[\gamma+\frac{\gamma(H-z)}{A+B}-\frac{C}{B}\right] \frac{A}{A-B} \times\left[(H-\mathrm{z})-y_{0}\left(\frac{y_{0}}{H-\mathrm{z}}\right)^{\frac{-B}{A}}\right]+\frac{\gamma\left[y_{0}{ }^{2}-(H-z)^{2}\right]}{A+B}+\frac{C}{B}\left(H-y_{0}-z\right)\right\}
$$

\section{Parametric studies}

\subsection{Cohesion}

Fig.11 shows the distribution of active earth pressure along the depth of the wall with different

values of cohesion. To obtain these data, the calculated parameters of the soil were based on the unit weight of the soil $\gamma=19.0 \mathrm{kN} / \mathrm{m}^{3}$, internal friction angle $\varphi=30^{\circ}$, wall height $\mathrm{H}=10 \mathrm{~m}$, and limit soil-wall 
interface angle $\delta=2 \varphi / 3$. Because active earth pressure at tension cracks is $0 \mathrm{kPa}$, the calculated value

366 of active earth pressure for the proposed method is not uniformly marked throughout this paper in $367 \quad$ Fig. 11.

368 According to Fig.11, active earth pressure gradually decreases with the increasing cohesion. The 369 distribution of active earth pressure still keeps linearly increasing at $0 \leq y \leq 0.6 H$, it does not 370 significantly decrease until the obvious arching effect appears near the bottom of the wall. In 371 addition, because tension cracks are considered in the proposed method, which is different from the 372 Rankine theory, the changes of active earth pressure near the top is slight with the increasing 373 cohesion. With the increasing depth, the effect of the cohesion on the active pressure gradually 374 increases. From Fig.11, active earth pressure at the bottom appears a negative value with the 375 increasing cohesion, which shows that tension cracks appear when the cohesion $c \geq 20 \mathrm{kPa}$. 376 Because the peak point of active earth pressure keeps moving up with increasing cohesion, it shows 377 that the position of the vertical soil arching also continues moving up. The results show the cohesion 378 is an important factor for arching effect.

\section{$379 \quad 4.2$ Friction angle}

380 Fig.12 shows the distribution of active earth pressure along the depth of the wall with different 381 friction angles. To obtain these data, the calculated parameters of the soil are based on the unit 382 weight of the soil $\gamma=19.0 \mathrm{kN} / \mathrm{m}^{3}$, cohesion $c=10 \mathrm{kPa}$, wall height $H=10 \mathrm{~m}$, and limit soil-wall 383 interface angle $\delta=2 \varphi / 3$.

384 Similarly, active earth pressure gradually decreases with the increasing internal friction angle. The upper active earth pressure basically increases linearly, and active earth pressure does not decrease rapidly until the stress deflection obviously occurs near the bottom of the wall. Moreover, as the 
internal friction angle increases, the height of tension cracks also increases gradually in Fig.12.

Fig.13 shows the variation of the average vertical stress with different depth and soil-wall interface friction angle. The average vertical stress can be obtained from Eq. (48) as a function of the depth and soil-wall interface friction angle. The calculated parameters of the soil were based on the soil-wall interface friction angle $\delta_{0}=0^{\circ}$, limit soil-wall interface friction angle $\delta=18^{\circ}$ and wall height $H=10 \mathrm{~m}$.

According to Fig.13, when $\delta_{m}=0^{\circ}$, the average vertical stress linearly increases with increasing

Fig.15 shows the coefficient variation of the average shear stress with different depth and 
409 and Eq. (24) as a function of the depth and displacement. To obtain the data, the calculated 410 parameters of the soil were based on the unit weight of the soil $\gamma=19.0 \mathrm{kN} / \mathrm{m}^{3}$, cohesion $c=20 \mathrm{kPa}$, 411 internal friction angle $\varphi=27^{\circ}$, initial soil-wall interface friction angle $\delta_{0}=0^{\circ}$, limit soil-wall interface 412 friction angle $\delta=18^{\circ}$ and the wall height $H=10 \mathrm{~m}$. The coefficient of the average shear stress at a 413 certain depth continuously increases with increasing displacement, and it gradually tends to a 414 constant value until the soil-wall mass arrives at the limit state. In addition, because of the increasing 415 depth of tension cracks, the coefficient of the average shear stress increases significantly at the depth $416 y / H=0.1$ than other depth. From Fig. 15 , the coefficient $(K)$ is always smaller than $\tan \varphi_{m}$. This result 417 shows that horizontal shear failure will not occur under normal conditions.

418 Fig.16 shows the distribution of active earth pressure along the depth of the wall considering soil 419 arching and horizontal shear stress or only soil arching. The parameters used for the soil are the same 420 as those mentioned above.

421 According to Fig.16, active earth pressure considering soil arching with horizontal shear stress is 422 smaller than that only considering soil arching. At the same time, this indicates that the influence of 423 the average shear stress gradually weakens with the displacement, and the horizontal shear stress 424 between the slices hinders the destruction of the soil. Therefore, the horizontal shear stress of the soil 425 slice can be used as a safe reserve for retaining wall's stability under normal conditions.

\section{Discussion and comparison of the results}

To check the applicability of the proposed method in cohesive-frictional soil and cohesionless soil, the predictions from the derived equation were compared with experimental values and other theory methods.

First, in cohesive-frictional soil, Yue (1992) conducted 11 sets of centrifuge model tests by a 
431 homemade hydraulic control device, which could control the displacement. The parameters of the 432 soil were based on the unit weight of the soil $\gamma=18.6 \mathrm{kN} / \mathrm{m}^{3}$, cohesion $c=38.2 \mathrm{kPa}$, internal friction 433 angle $\varphi=22.7^{\circ}$, wall height $H=250 \mathrm{~mm}$, and model rate of 80.18 . In the test, the horizontal 434 displacement of retaining wall arriving at the limit state is $s=2.7 \mathrm{~mm}$. According to Fig. 17 , the 435 measured values of lateral earth pressure are mainly distributed on both sides of the calculated values 436 of the proposed method. The results showed that the calculated values of the proposed method were 437 in good agreement with the measured values. The measured resultant force of active earth pressure 438 was approximately $698.24 \mathrm{kN}$, the calculated value of the proposed method was $677.75 \mathrm{kN}$, and the 439 calculated value of Rankine theory was $788.11 \mathrm{kN}$.

440 Secondly, in cohesionless soil, Tsagareli (1965) measured the distribution of active earth pressure 441 under the translation mode. The parameters of the soil were based on the unit weight of the soil $442 \gamma=18.0 \mathrm{kN} / \mathrm{m}^{3}$, cohesion $c=0 \mathrm{kPa}$, internal friction angle $\varphi=37^{\circ}$, wall height $H=4 \mathrm{~m}$, and critical 443 soil-wall interface angle $\delta=2 \varphi / 3$. From Fig.18, the calculated values of the proposed method were 444 good agreement with Rankine theory at $0 \leq y \leq 0.5 H$. The significant differences appeared at the 445 bottom due to the arching effect. The measured resultant force of active earth pressure was approximately $40.06 \mathrm{kN}$, the calculated value of the proposed method was $33.04 \mathrm{kN}$, the calculated value of Rankine theory was $35.80 \mathrm{kN}$, and the calculated value of Handy's method was $29.58 \mathrm{kN}$.

448 Therefore, the calculated values of active earth pressure for the proposed method were basically 449 consistent with the measured values and other theoretical methods.

\section{Summary and Conclusions}

The estimation of the lateral earth pressure acting on retaining wall is extremely important in practical engineering. The simple model for the classical Rankine theory and Coulomb theory has 
been widely applied in practice. However, the lateral earth pressure behind the wall is mostly in the 454 intermediate state with the increasing displacement, and its distribution is nonlinear. Although some had attempted to estimate active earth pressure considering arching effect, the displacement and the effect of soil arching exist mutually, but most studies consider them separately and ignore the influence of rotation angle and horizontal shear stress. In this paper, a new formulation for the non-limit active earth pressure is derived for cohesive-frictional soil, which is based on the horizontal slices and static equilibrium method. The relevant features of the proposed method are summarized below:

(1) The influence of the displacement and the arching effect was considered in the proposed potential rupture angle, depth of tension cracks, rotation angle, and horizontal average shear stress.

(2) The variation of the mobilized internal friction angle and soil-wall interface friction angle for cohesive-frictional soil with the displacement was performed by comparing the FEM and other theoretical methods. It shows that the empirical formulations for the mobilized soil-wall interface friction angle and internal friction angle are still applicable to cohesive-frictional soil.

(3) A formulation of the rupture angle was derived by considering the cohesion, soil-wall interface friction angle, wall height and the unit weight. Depth of tension cracks was calculated considering the influence of the arching effect and cohesion of the soil-wall interface. The formulation of the rupture angle and tension cracks can better reflect the actual situation in cohesive-frictional soil by compared with other methods.

(4) By comparing the experimental results and other theoretical methods, it was concluded that the proposed analytical procedure could reliably calculate the non-limit active earth pressure, lateral resultant force, rupture angle, depth of tension cracks, mobilized internal friction angle and soil-wall 

interface friction in cohesive-frictional soil.

\section{Data Availability Statement}

478 All data generated or analyzed during this study are included within the article.

\section{Acknowledgments}

480 The study was supported by the National Natural Science Foundation of China (Grant 41272333),

481 National Program on Key Basic Research Project of China (Grant 2011CB013501).We express our 482 gratitude for this financial support.

483 https://github.com/jjf524973903/Theoretical-analysis-for-lateral-earth-pressure-considering-arching-

484 effect-in-cohesive-soil

485 Conflict of interest

486 The authors declare that they have no conflict of interest.

487 Notation

488 The following symbols are used in this paper:

$489 \quad H=$ total height of retaining wall

$490 \quad s=$ displacement of retaining wall

$491 \quad z=$ depth of tension cracks

$492 \quad b=$ width of tension cracks zone

$493 y=$ arbitrarily depth of retaining wall

$494 \quad \beta=$ rupture angle

495

$\varepsilon=$ rotational angle of retaining wall

$496 \quad \gamma=$ unit weight 


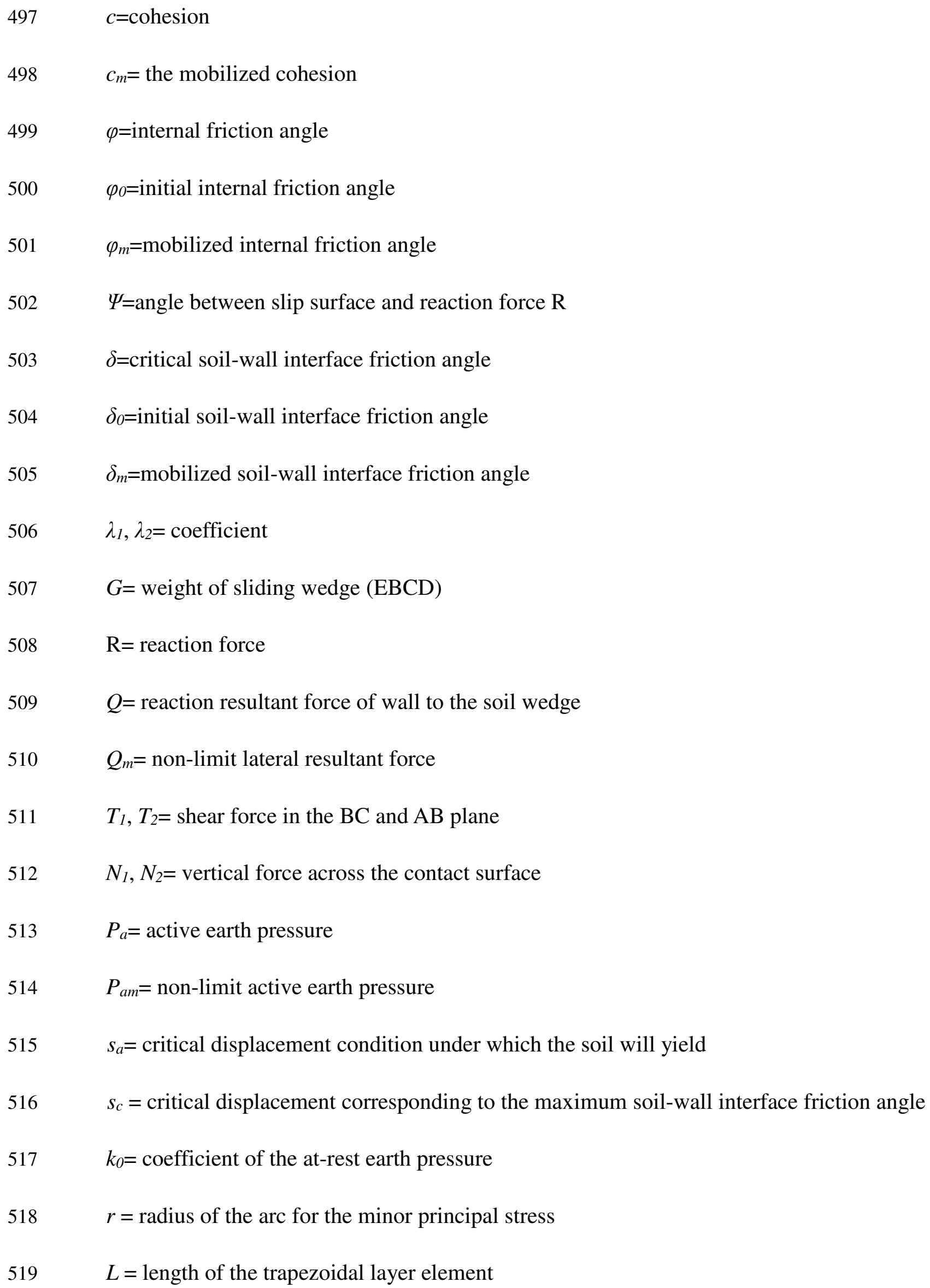


$K_{a w}=$ coefficient of the lateral active earth pressure

$K_{a w n}=$ coefficient of the average non-limit active earth pressure

$K=$ coefficient of the horizontal average shear stress

$T=$ the shear force acting on retaining wall in the FEM method

$$
N=\text { resultant force of the lateral earth pressure acting on retaining wall in the FEM method }
$$

$$
\sigma_{1}=\text { major principal stress }
$$

$$
\sigma_{3}=\text { minor principal stress }
$$

$\sigma_{\mathrm{av}}=$ average vertical stress

\section{References}

529 Ahmadabadi, M., Ghanbari. A., 2009. New procedure for active earth pressure calculation in 530 retaining walls with reinforced cohesive-frictional backfill. Geotextiles and Geomembranes, $531 \quad$ Vol.27:456- 463. https://doi.org/10.1016/j.geotexmem.2009.06.004 .

532 Bang, S., 1985. Active earth pressure behind retaining walls. Journal of Geotechnical Engineering, Vol.111 (3):407-412. https://doi.org/10.1061/(asce)0733-9410(1985)111:3(407).

534 Coulomb, 1776.C.A: Essias sur une application des maximis et minimis a quelques problems de 535 statique relatits a larchitecture. Mémoires de l'Académie Royale des Sciences presents par divers $536 \quad$ Savans, Paris 5, 7.

537 Clough, G.W., and Duncan, J.M., 1971. Finite element analysis of retaining wall behavior. Journal of $538 \quad$ Geotechnical Engineering, Vol.97 (12):1657-1673.

539 Clough, G.W., Duncan, J.M., 1991. Earth pressure. In foundation engineering handbook. 2nd ed. 540 Edited by H.-Y. Fang. Van Nostrand Reinhold, New York. pp. 223-235.

541 Chang, M.F., 1997. Lateral earth pressures behind rotating walls. Canadian Geotechnical Journal, 
1997, Vol.46:498-509. https://doi.org/10.1139/t97-016.

543 Chen, J.X., Song, W.W., 2019. Non-limit active earth pressure for retaining wall under translational 544 motion. Rock and Soil Mechanics, Vol.40(6): 2284-2292.

545 Fang, Y.S., Ishibashi, I., 1986. Static earth pressure with various wall movements. Journal of https://doi.org/10.1061/(asce)0733-9410(1986)112:3(317) .

Golam, M., Alireza, A., 2015. Experimental and numerical investigation of arching effect in sand using modified Mohr Coulomb. Geomechanics and Engineering, Vol.8 (6):829-844. https://doi.org/10.12989/gae.2015.8.6.829

Gong, X.N., Xie, K.H., 2014. Soil Mechanics. China Building Industry Press, 149-161.

Handy, L.R., 1985. The arch in soil arching. Journal of Geotechnical Engineering, 111(3):302-318. https://doi.org/10.1061/(asce)0733-9410(1985)111:3(302) . Engineering, 31(3): 526-529.https://doi.org/10.1016/j.soildyn.2010.10.001 .

Jiang, M.J., He, J., Wang, J.F., Liu, F., et al, 2014. Distinct simulation of earth pressure against a rigid retaining wall considering inter-particle rolling resistance in sandy backfill. Granular Matter, 16(5), 797-814. https://doi.org/10.1007/s10035-014-0515-3 .

Khosravi, M.H., Pipatpongsa, T., Takemura, J., 2016. Theoretical analysis of earth pressure against rigid retaining walls under translation mode. Soil and Foundations, Vol.54 (4):664-675.https://doi.org/10.1016/j.sandf.2016.07.007 .

Kingsley, H.W.,1989. Arch in soil arching. Journal of Geotechnical Engineering, 115(3):415-419.https://doi.org/10.1061/(asce)0733-9410(1989)115:3(415) .

Kumar, S.S., 2010. Dynamic active thrust from c- $-\varphi$ soil backfills. Soil Dynamics and Earthquake

Li, M.G., Chen, J.J., Wang, J.H., 2017. Arching effect on lateral pressureof confined granular 
material: numerical and theoretical analysis. Granular Matter, 1-11.doi 10.1007/s 10035-017-0700-2.https://doi.org/10.1016/j.soildyn.2010.10.001 .

Lou, P.J., 2015. A method to calculate active earth pressure with considering soil arching effect under the non-limit state of clayey soil. Rock and Soil Mechanics, Vol.36(04): 988 - 994.

Matsuo, M., Kenmochi, S., Yagi, H., 1978 .Experimental study on earth pressure of retaining wall by field tests. Soils and foundations, Vol.18 (3):27-41.https://doi.org/10.3208/sandf1972.18.3_27 .

Mayne, P. W. and Kulhawy, F. H. 1983. K-OCR relationships in soil, International Journal of Rock Mechanics and Mining Sciences \& Geomechanics Abstracts, 20(1): A2. doi: 10.1016/0148-9062(83)91623-6.

Mei, G.X., Chen, Q.M., Song L.H., 2009. Model for predicting displacement dependent later earth pressure. Canadian Geotechnical Journal, Vol.46:969- 975.https://doi.org/10.1139/t09-040 .

Mazindrani, Z.H., M. H. Ganjal. Lateral earth pressure problem of cohesive backfill with inclined $\begin{array}{llll}\text { surface. } & \text { Canadian } & \text { Geotechnical Journal, } & 1997,\end{array}$ https://doi.org/10.1061/(asce)1090-0241(1997)123:2(110) .

Ni, P., Mangalathu, S., Song, L., Mei, G., Zhao, Y., 2018. Displacement-dependent lateral earth pressure models. Journal of Engineering Mechanics, 144(6): 04018032. https://doi.org/10.1061/(asce)em.1943-7889.0001451 .

Paik. K.H., Salgado, R., 2003. Estimation of active earth pressure against rigid retaining walls considering arching effects. Géotechnique, https://doi.org/10.1680/geot.2003.53.7.643 .

Quinlan, J.F., 1987. Discussion of "The arch in soil arching” by R.L. Hand. Journal of Geotechnical Engineering,ASCE, 113(3):272-274. https://doi.org/10.1061/(asce)0733-9410(1987)113:3(272) .

Rankine, W.J.M., 1857. On the stability of loose earth. Philos. Trans. R. Soc.Lond. 147, 9-27. 
Rao,P.P., Chen, Q.S., Zhou, Y.T., Nimbalkar, S., Chiaro, G., 2016. Determination of active earth pressure on rigid retaining wall considering archingeffect in cohesive backfill soil. International Journal of Geomechanics, 16(3): 04015082.https://doi.org/10.1061/(asce)gm.1943-5622.0000589 .

Spangler, M.G., Handy, R. L., 1984. Soil engineering. New York: Harper \&Row, 1984.

Terzaghi, K., 1934. Large retaining wall tests I-pressure of dry sand. Engineering News Record, 112(1): 136-140.

Tu, B.X., Jia, J.Q., 2012. Research on active earth pressure behind rigid research wall from cohesive soiley backfill considering soil arching effects. Chinese Journal of Rock Mechanics and Engineering, Vol.31 (05): 1064-1070.

Tsagareli, Z.V., 1965. Experimental investigation of the pressure of a loose medium on retaining wall with vertical back face and horizontal backfill surface. Soil Mechanics. 91(4), 197-200.https://doi.org/10.1007/bf01706095 .

Vahedifard, F., Leshchinsky, B.A.,Mortezaei, K., Lu, N., 2015. Active earth pressures for unsaturated retaining structures. Journal of Geotechnical and Geoenvironmental engineering, 2015, 141(11): 04015048.https://doi.org/10.1061/(asce)gt.1943-5606.0001356 .

Venanzio G.R., 2010. Discussion of "active earth pressure on retaining wall for $c-\varphi$ soil backfill under seismic loading condition" by S. K.Shukla, S. K. Gupta, and N. Sivakugan. Journal of Geotechnical and Geoenvironmental Engineering, 136: 1583-1584. https://doi.org/10.1061/(asce)gt.1943-5606.0000276 .

Wang, S.C., Sun, B.J., Shao, Y., 2015. Modified computational method for active earth pressure. Rock and Soil Mechanics. Vol.36(5), 1375-1379.

Xu, R.Q., Liao, B., Wu, J., Chang, S., 2013. Computational method for active earth pressure of cohesive soil under non-limit state. Rock and Soil Mechanics. Vol.34 (1), 148-154. 
611 Yue, Z.R., Peng, Y.Z., Zhang, S.D., 1992. Centrifuge model tests on lateral pressure on walls 612 retaining wall compacted cohesive soiley backfill. Chinese Journal of Geotechnical Engineering, $613 \quad$ Vol.14 (06) , 90-96.

614 Zhou Y.Y., Ren M.L.1990. An experimental study on active earth pressure behind rigid retaining wall. 615 Chinese Journal of Geotechnical Engineering, 12(2): 19-26.

616 Zhao, C.G., Bai, B., 2004. Fundamentals of soil mechanics. Tsinghua University Press and Beijing 617 Jiaotong University Press, 197-290.

618 Zhu, J.M., Zhao, Q., Lin, Q.T., Zhen, J.Y., et al, 2015. Study on calculation Method of soil arch 619 effect. China University of Mining and Technology Press, 1-44. 
621 Table 1 Material parameters used in the finite element model

622 Table 2 Calculated results of the finite element model

623 Fig. 1 Finite element analytical model for the lateral earth pressure

624 Fig. 2 Variation of resultant force of the lateral earth pressure with the wall movement

625 Fig. 3 Comparison of the mobilized soil-wall interface friction angles under different methods and conditions

627 Fig.4 Comparison of the mobilized internal friction angles under different methods and conditions

628 Fig. 5 Trajectory of the minor principal stress in the differential element of the sliding wedge

629 Fig. 6 Mohr's circle representation of the stresses on point A (a) and the stress analysis in the sliding wedge $(b, c)$

631 Fig. 7 Static equilibrium of the soil-wall system

632 Fig. 8 Comparison between the proposed method and other theoretical methods for tension cracks

633 Fig. 9 Comparison between the proposed method and other theoretical methods on the potential rupture angle

635 Fig. 10 Forces acted on the $A B$ trapezoidal layer element

636 Fig. 11 Change of active earth pressure distribution with different cohesion

637 Fig. 12 Change of active earth pressure distribution with different friction angle

638 Fig. 13 Variations of the average vertical stress with different depth and soil-wall interface friction angle

640 Fig. 14 Change in $K_{a w n}$ with different critical soil-wall interface friction angle and displacement

641 Fig. 15 Change in $K$ with different depth and displacement

642 Fig. 16 Comparison of the lateral earth pressure distribution considering soil arching and shear stress 
or only soil arching

644 Fig. 17 Comparison between predicted and experimental values obtained about lateral earth pressure 645 in cohesive-frictional soil

646 Fig. 18 Comparison between predicted and experimental values obtained about active earth pressure 647 in cohesionless soil 
648 Table 1 Material parameters used in the finite element model

\begin{tabular}{lccc}
\hline Parameters & Silty sand & Concrete & Soil-wall interface \\
\hline Unit weight $\left(\gamma, \mathrm{kN} / \mathrm{m}^{3}\right)$ & 19.40 & 25.00 & $/$ \\
Cohesion $(c, \mathrm{kPa})$ & 23.00 & $/$ & $/$ \\
Internal friction angle $\left(\varphi,{ }^{\circ}\right)$ & 27.00 & $/$ & $/$ \\
Elastic modulus $(\mathrm{E}, \mathrm{MPa})$ & 0.75 & 30000 & $/$ \\
Poisson ratio $(v)$ & 0.32 & 0.20 & $/$ \\
Normal stiffness ratio coefficient & $/$ & $/$ & 1 \\
Tangential stiffness proportional coefficient & $/$ & $/$ & 0.1 \\
\hline
\end{tabular}

649 Table 2 Calculated results of the finite element model

\begin{tabular}{|c|c|c|c|c|c|}
\hline $\begin{array}{l}\text { Calculation } \\
\text { Steps }\end{array}$ & $\begin{array}{c}\text { Max } \\
\text { horizontal } \\
\text { displacement } \\
s(\mathrm{~mm})\end{array}$ & $\begin{array}{l}\text { Horizontal lateral } \\
\text { resultant force } \\
\qquad N(k N)\end{array}$ & $\begin{array}{c}\text { Shear force } \\
\quad T(k N)\end{array}$ & $\begin{array}{c}\text { Internal frictional } \\
\text { angle } \\
\varphi_{m}\left({ }^{\circ}\right)\end{array}$ & $\begin{array}{c}\text { Soil-wall interface } \\
\text { frictional angle } \\
\delta_{m}\left(^{\circ}\right)\end{array}$ \\
\hline Step 1 & 0 & 304.24 & 38.13 & 17.49 & 3.28 \\
\hline Step 2 & 4.1 & 294.43 & 41.88 & 17.90 & 3.67 \\
\hline Step 3 & 8.3 & 284.67 & 46.65 & 18.31 & 4.17 \\
\hline Step 4 & 12.5 & 274.94 & 52.22 & 18.73 & 4.76 \\
\hline Step 5 & 16.6 & 265.23 & 58.41 & 19.16 & 5.43 \\
\hline Step 6 & 21.2 & 255.55 & 65.06 & 19.59 & 6.18 \\
\hline Step 7 & 25.7 & 245.90 & 72.07 & 20.03 & 6.99 \\
\hline Step 8 & 30.2 & 236.28 & 79.33 & 20.48 & 7.86 \\
\hline Step 9 & 34.8 & 226.69 & 86.79 & 20.94 & 8.79 \\
\hline Step 10 & 39.5 & 217.11 & 94.41 & 21.41 & 9.78 \\
\hline Step 11 & 44.2 & 207.56 & 102.14 & 21.88 & 10.83 \\
\hline Step 12 & 49.0 & 198.03 & 109.97 & 22.37 & 11.93 \\
\hline Step 13 & 53.8 & 188.50 & 117.87 & 22.86 & 13.11 \\
\hline Step 14 & 58.7 & 178.99 & 125.83 & 23.37 & 14.34 \\
\hline Step 15 & 63.6 & 169.49 & 133.84 & 23.89 & 15.65 \\
\hline Step 16 & 68.5 & 160.00 & 141.88 & 24.43 & 17.04 \\
\hline Step 17 & 73.4 & 150.51 & 149.96 & 24.98 & 18.50 \\
\hline Step 18 & 78.4 & 141.03 & 158.06 & 25.55 & 20.06 \\
\hline Step 19 & 83.5 & 131.55 & 166.07 & 26.14 & 21.70 \\
\hline Step 20 & 90.4 & 121.92 & 171.16 & 26.75 & 23.10 \\
\hline Step 21 & 99.3 & 112.33 & 173.28 & 27.00 & 24.02 \\
\hline
\end{tabular}




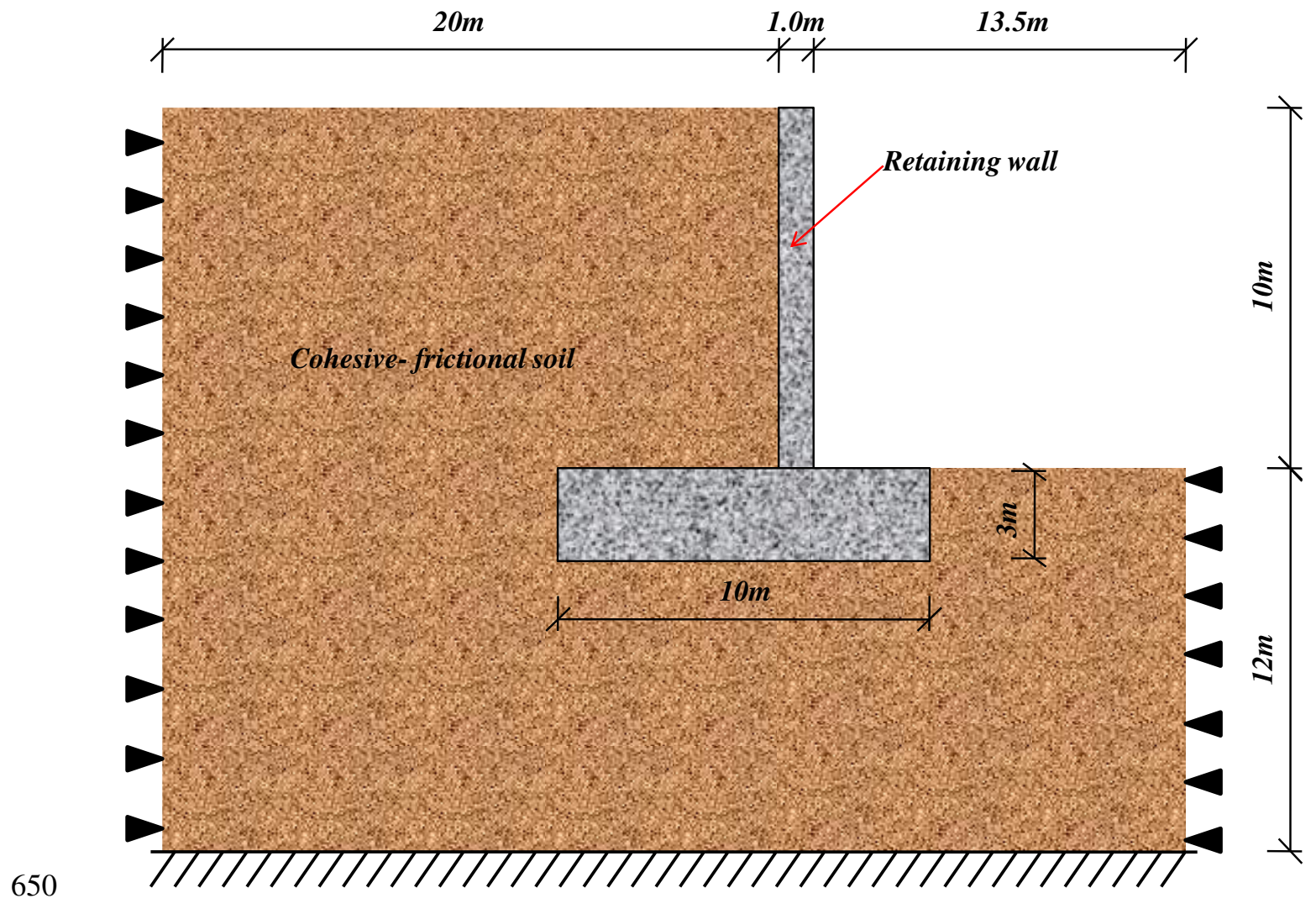

651 Fig. 1 Finite element analytical model for the lateral earth pressure 


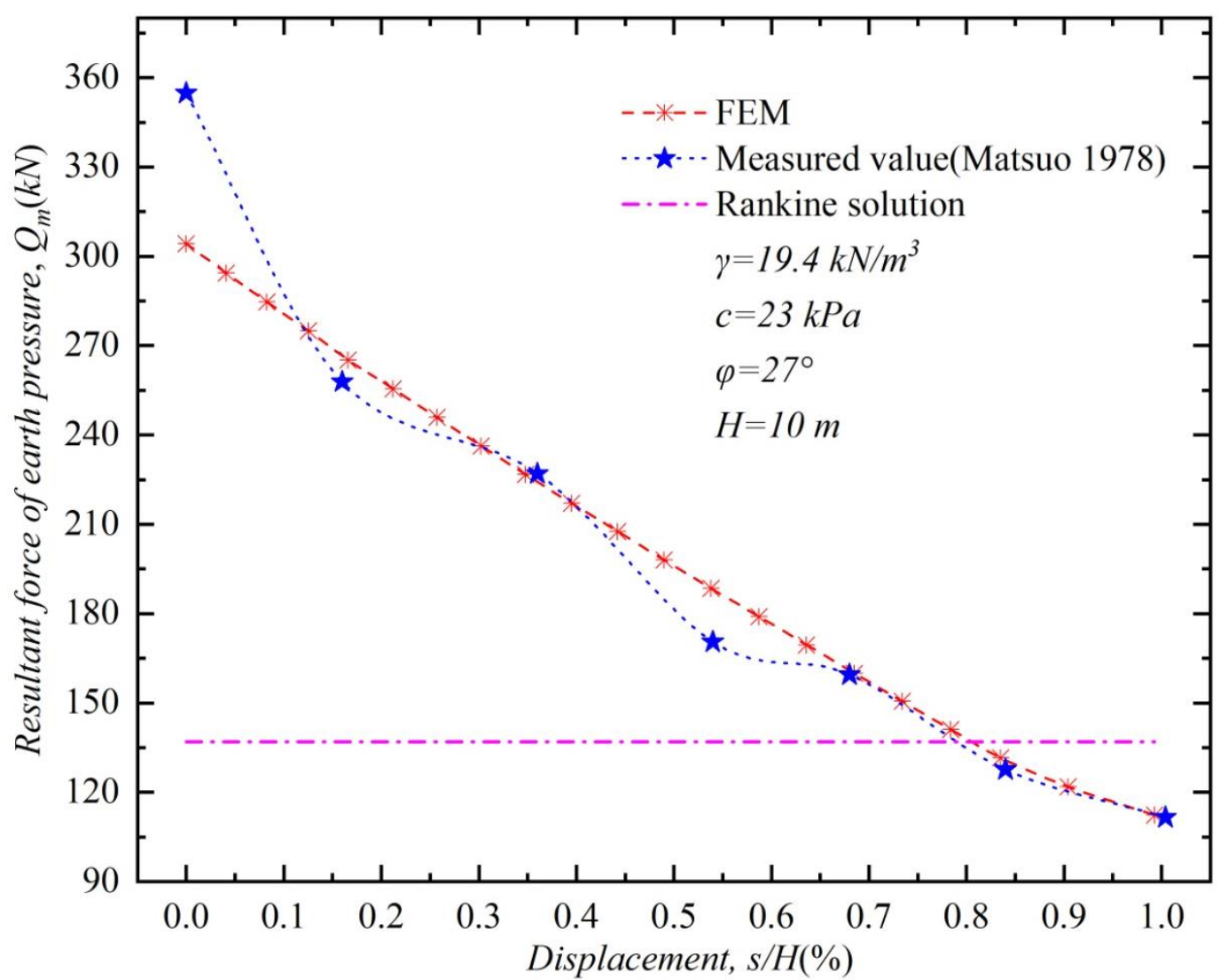

653 Fig. 2 Variation of resultant force of the lateral earth pressure with the wall movement 


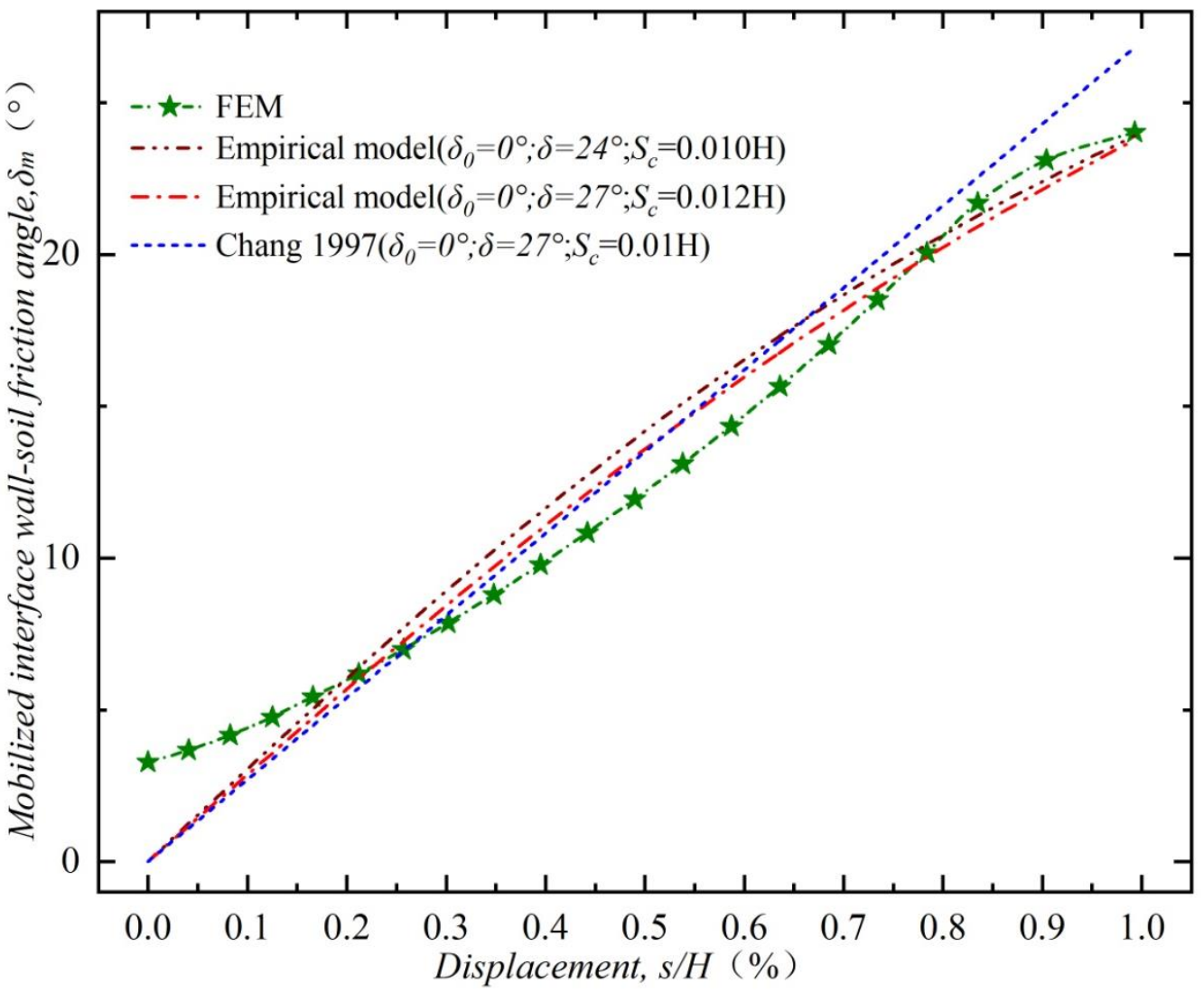

654

Displacement, s/H (\%)

655 Fig. 3 Comparison of the mobilized soil-wall interface friction angles under different methods and 656 conditions 


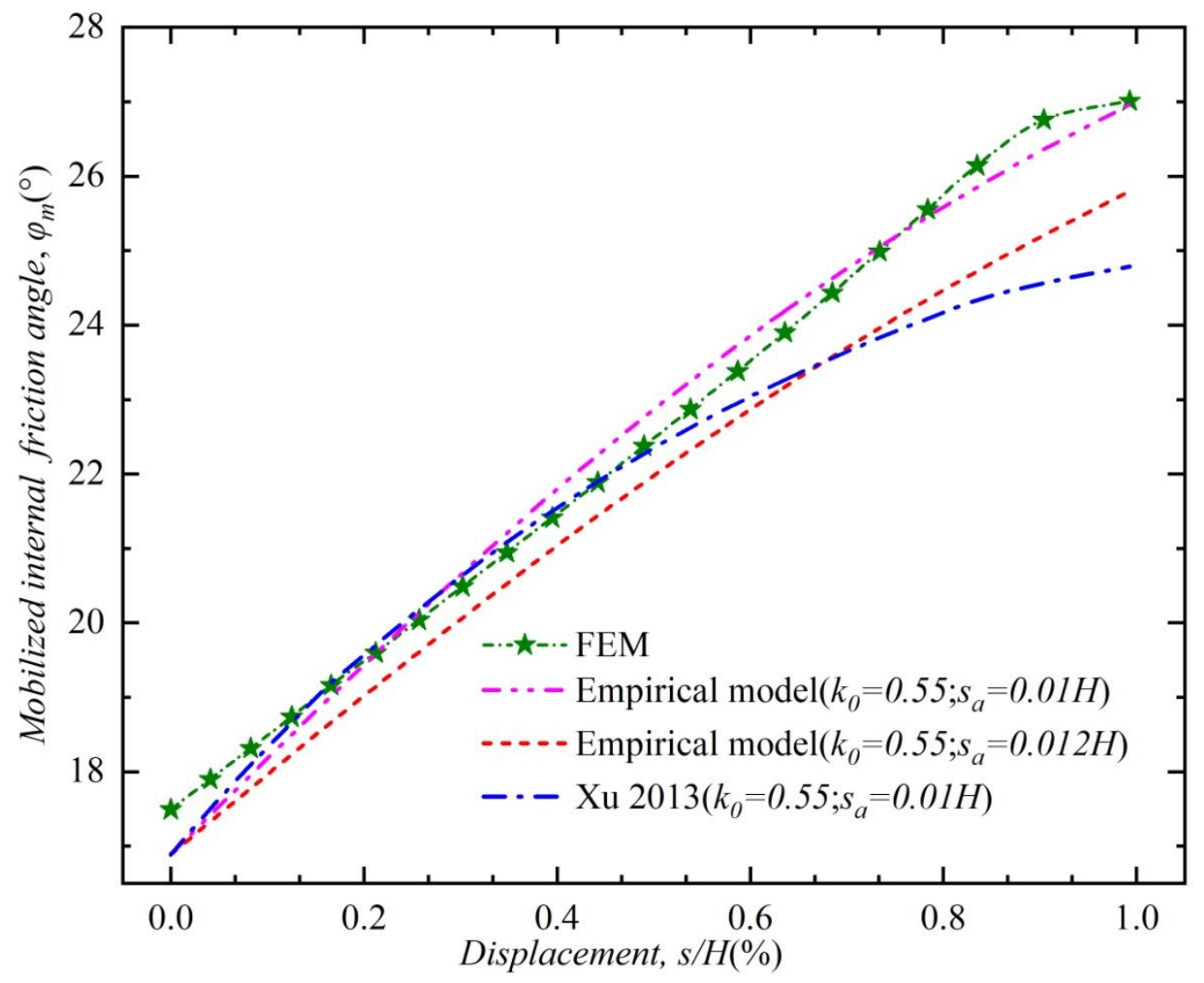

658 Fig.4 Comparison of the mobilized internal friction angles under different methods and conditions 


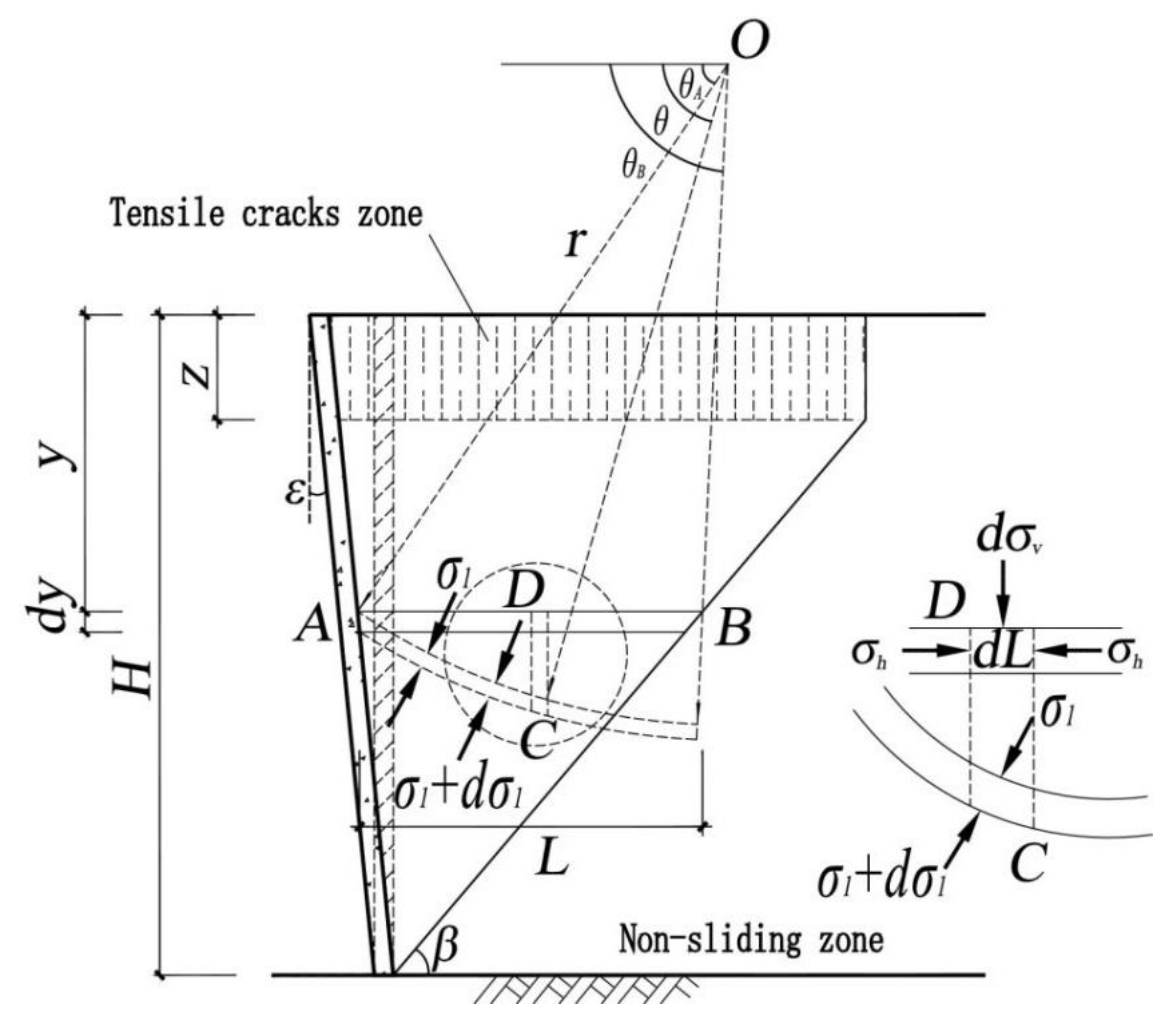

660 Fig. 5 Trajectory of the minor principal stress in the differential element of the sliding wedge 


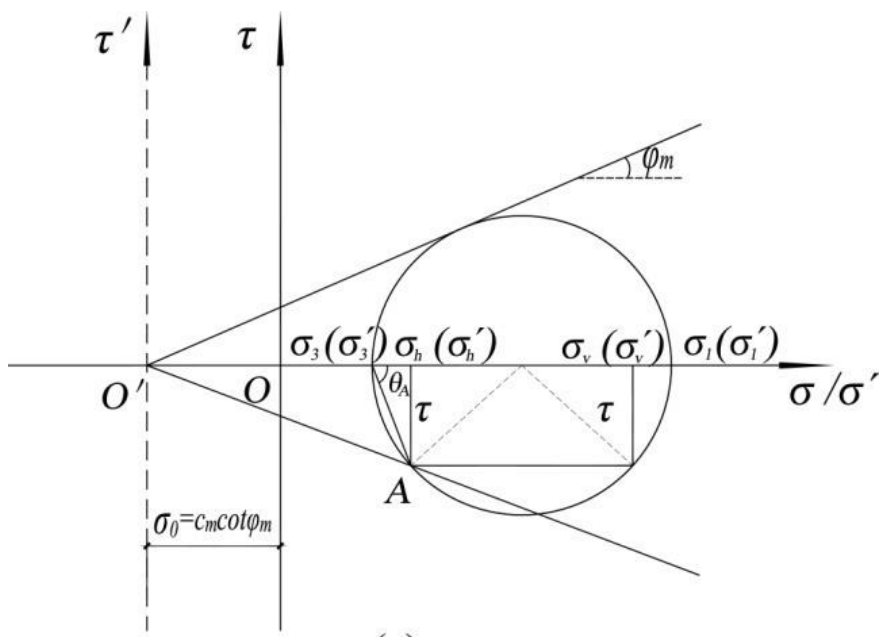

661

(a)

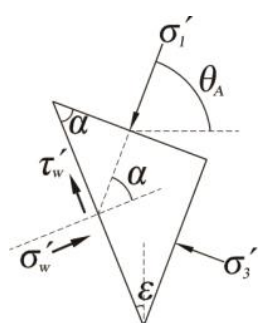

A point

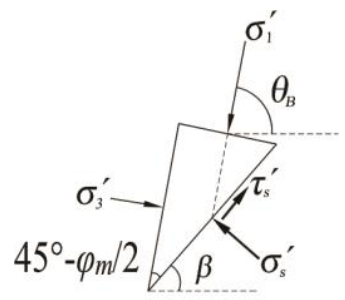

B point

662

(b)

(c)

663 Fig. 6 Mohr's circle representation of the stresses on point A (a) and the stress analysis in the sliding 664 wedge $(b, c)$ 


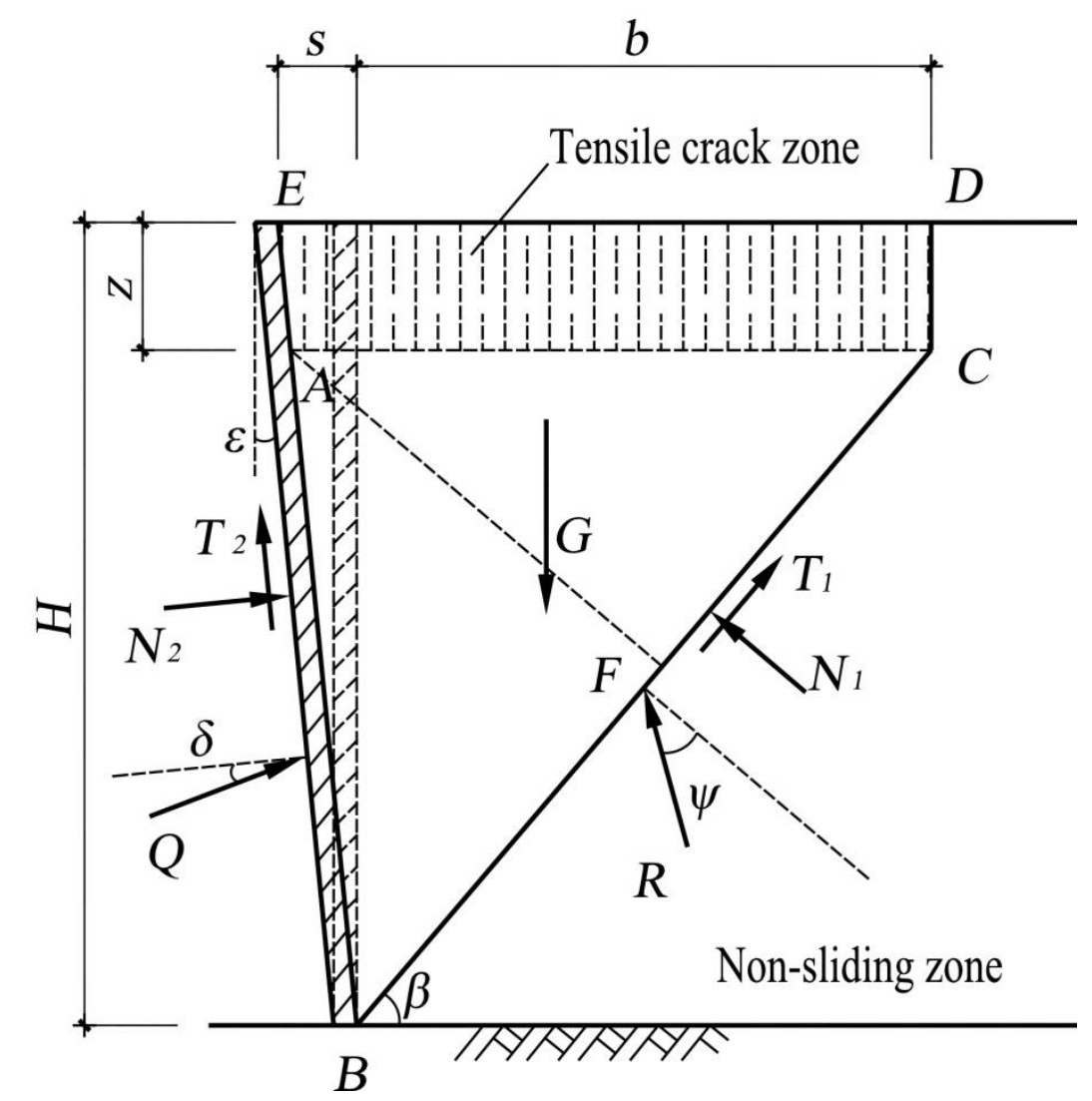

666 Fig. 7 Static equilibrium of the soil-wall system 


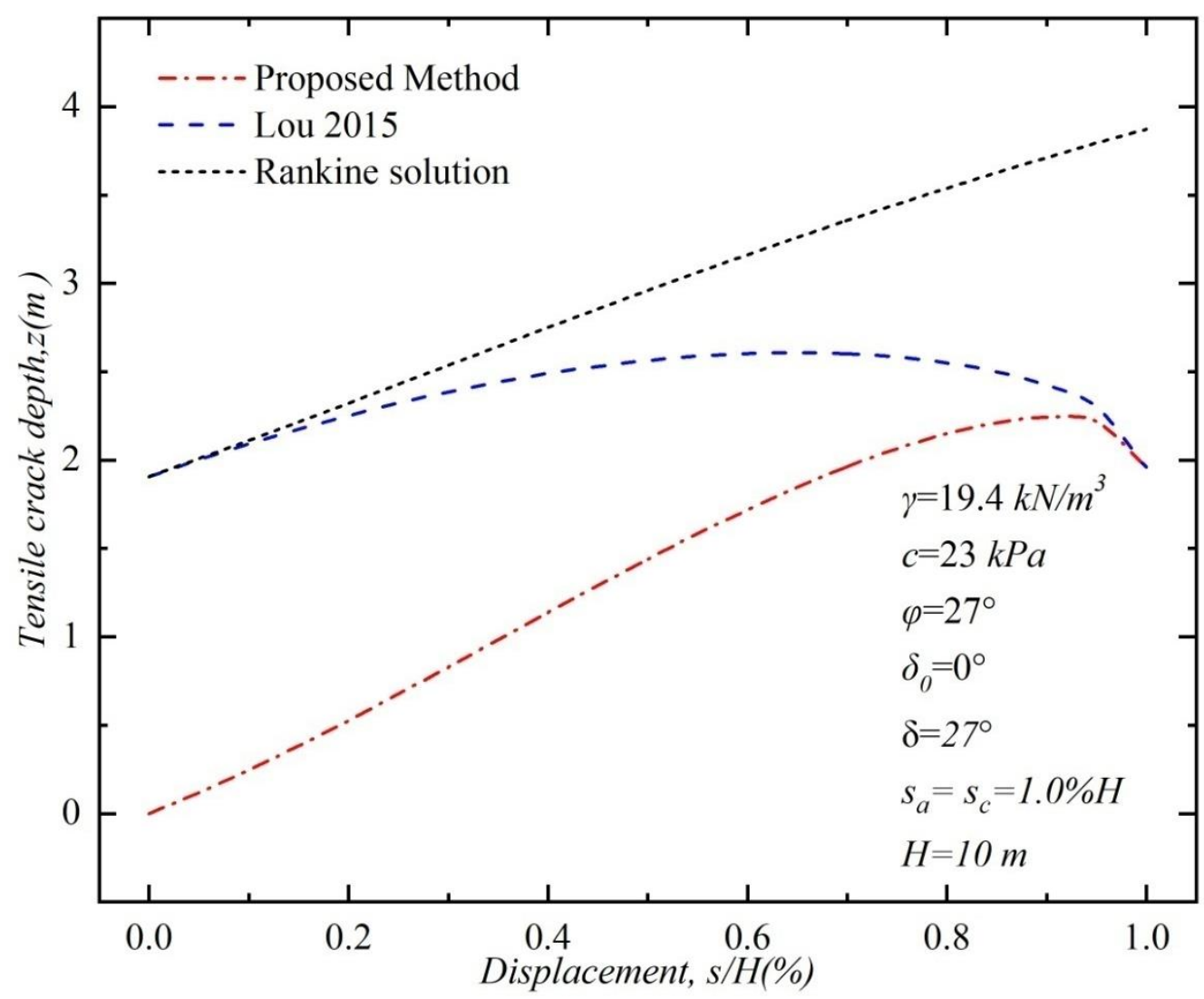

Fig. 8 Comparison between the proposed method and other theoretical methods for tension cracks 


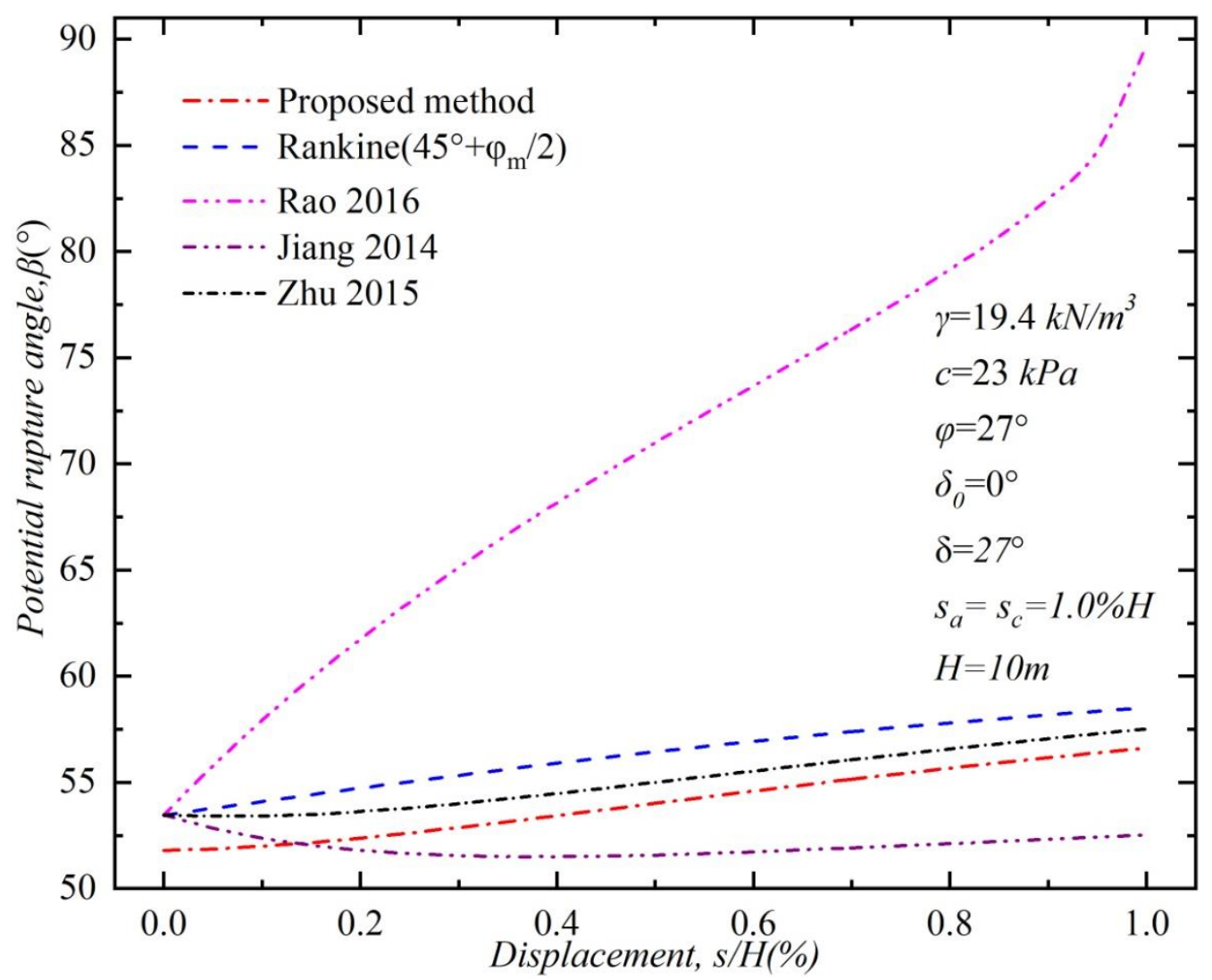

670 Fig. 9 Comparison between the proposed method and other theoretical methods on the potential 671 rupture angle 


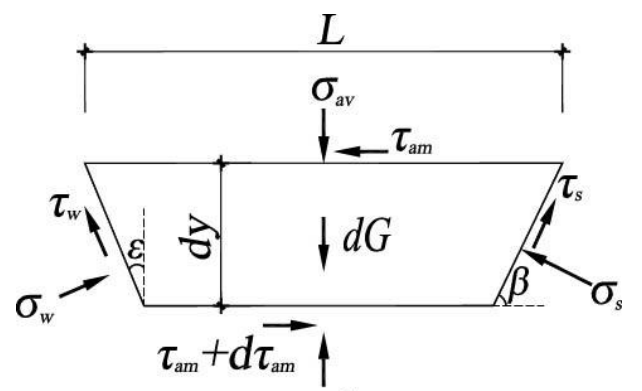

672

$\sigma_{a v}+d \sigma_{a v}$

673 Fig. 10 Forces acted on the $A B$ trapezoidal layer element 


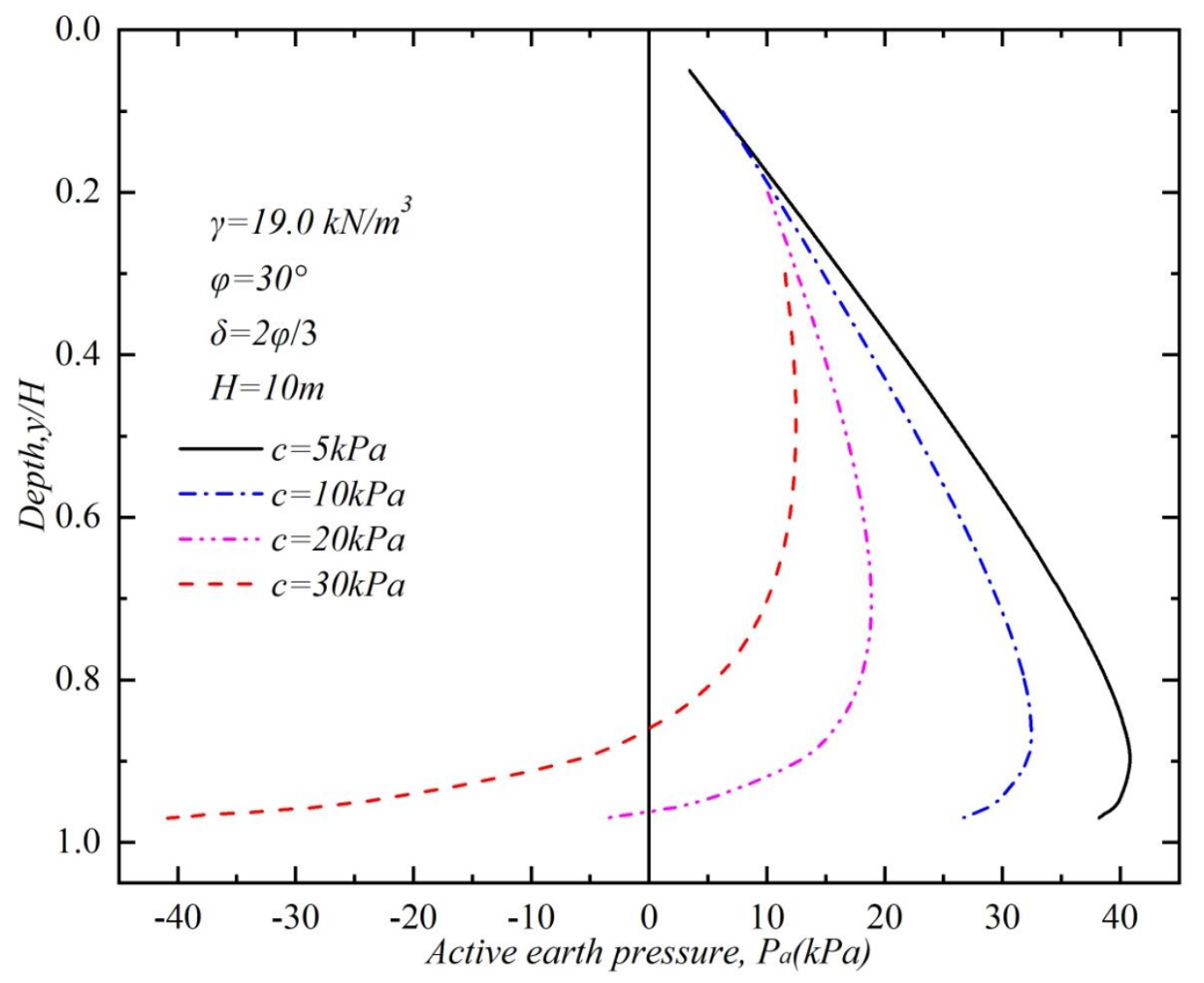

674

675 Fig. 11 Change of active earth pressure distribution with different cohesion 


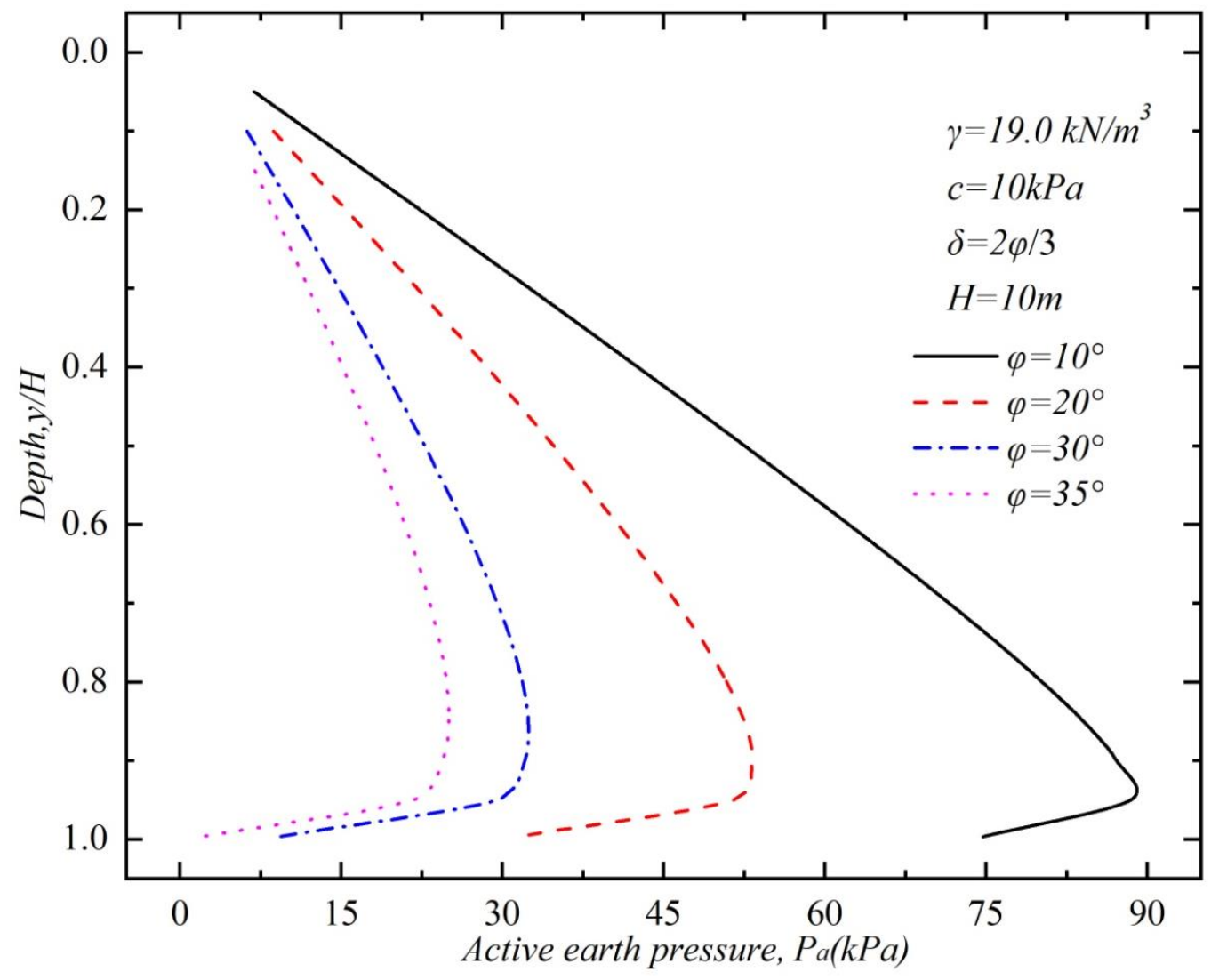

676

677 Fig. 12 Change of active earth pressure distribution with different friction angles 


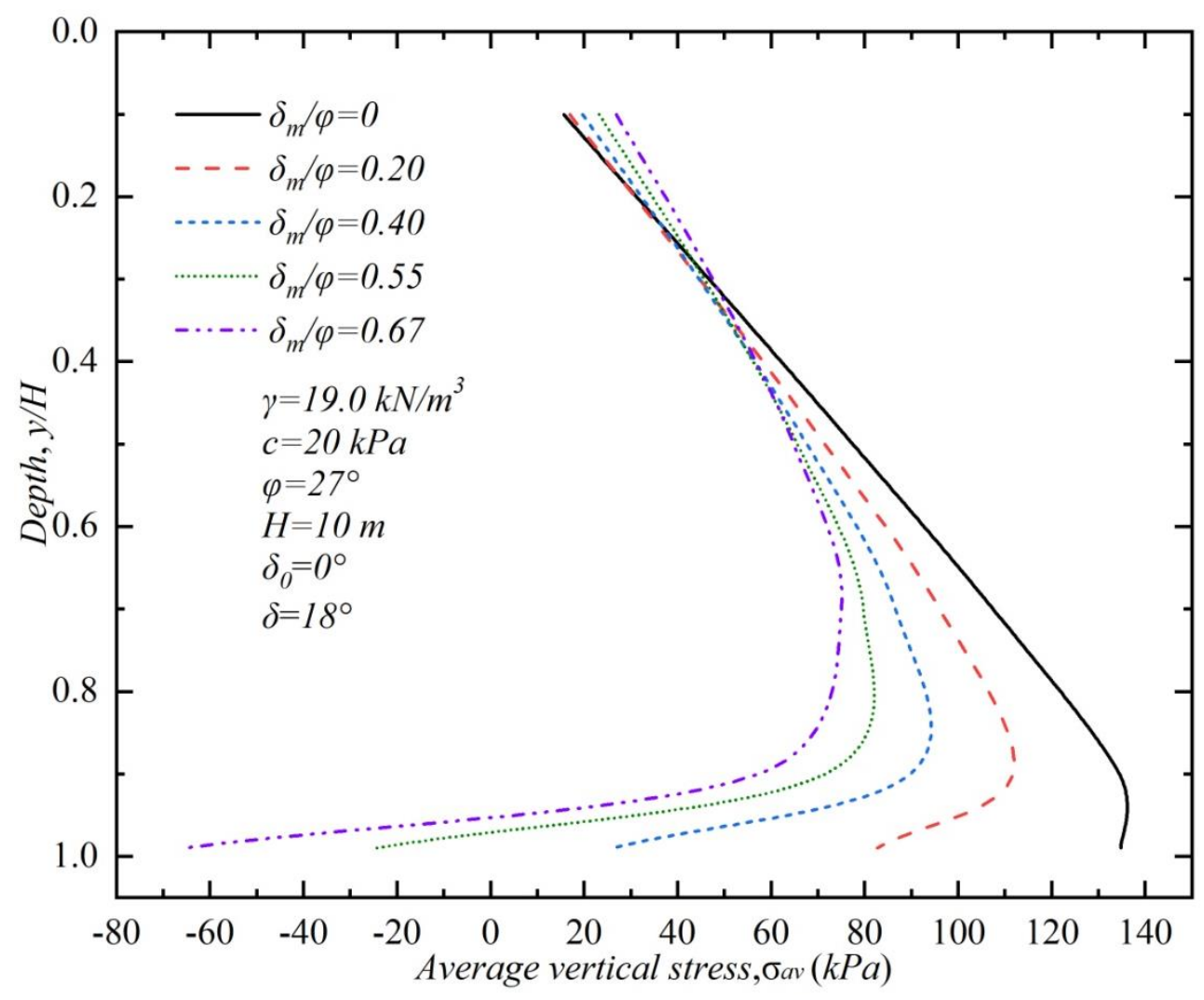

679 Fig. 13 Variations of the average vertical stress with different depth and soil-wall interface friction 680 angle 


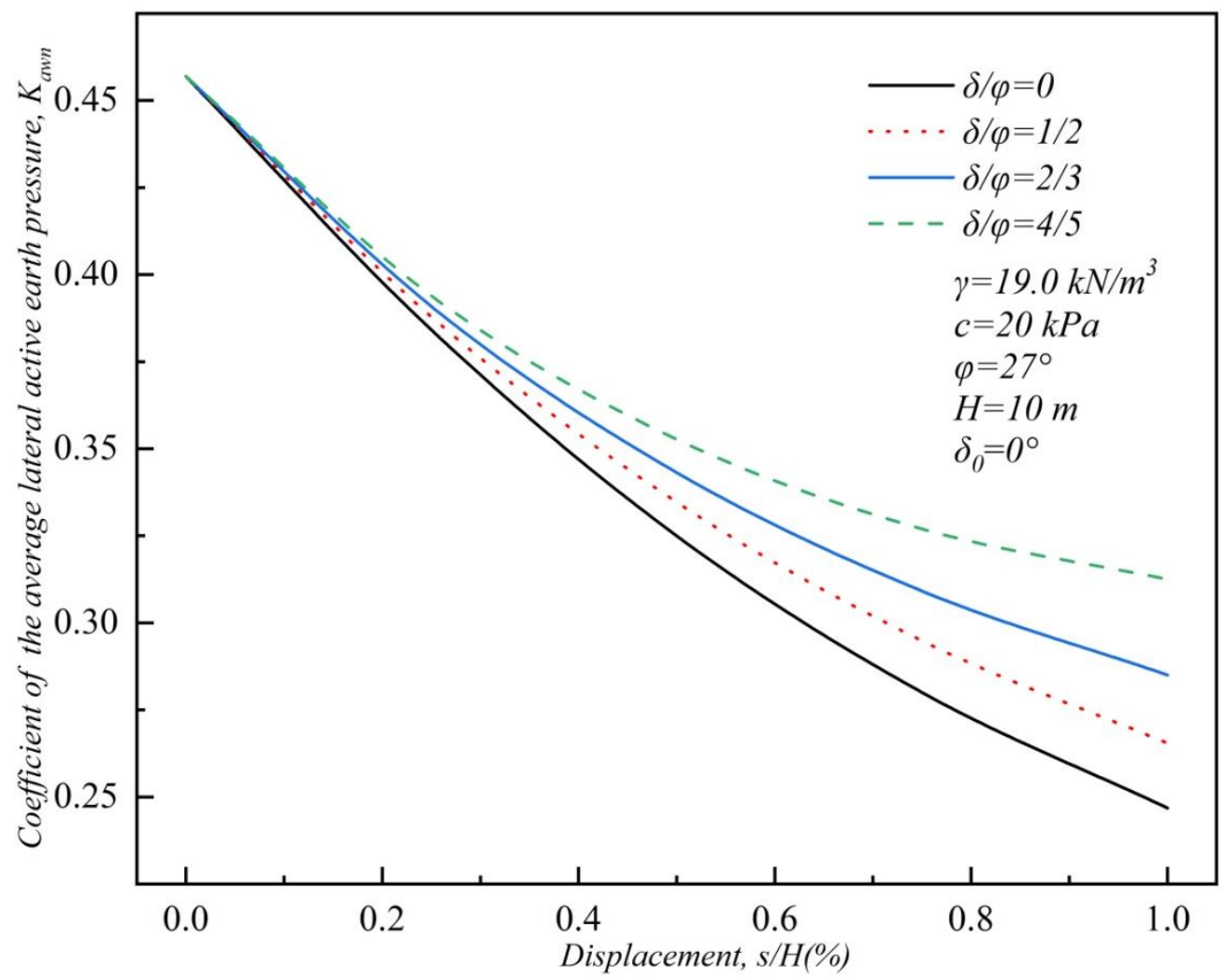

681 Fig. 14 Change in $K_{a w n}$ with different critical soil-wall interface friction angle and displacement 682 


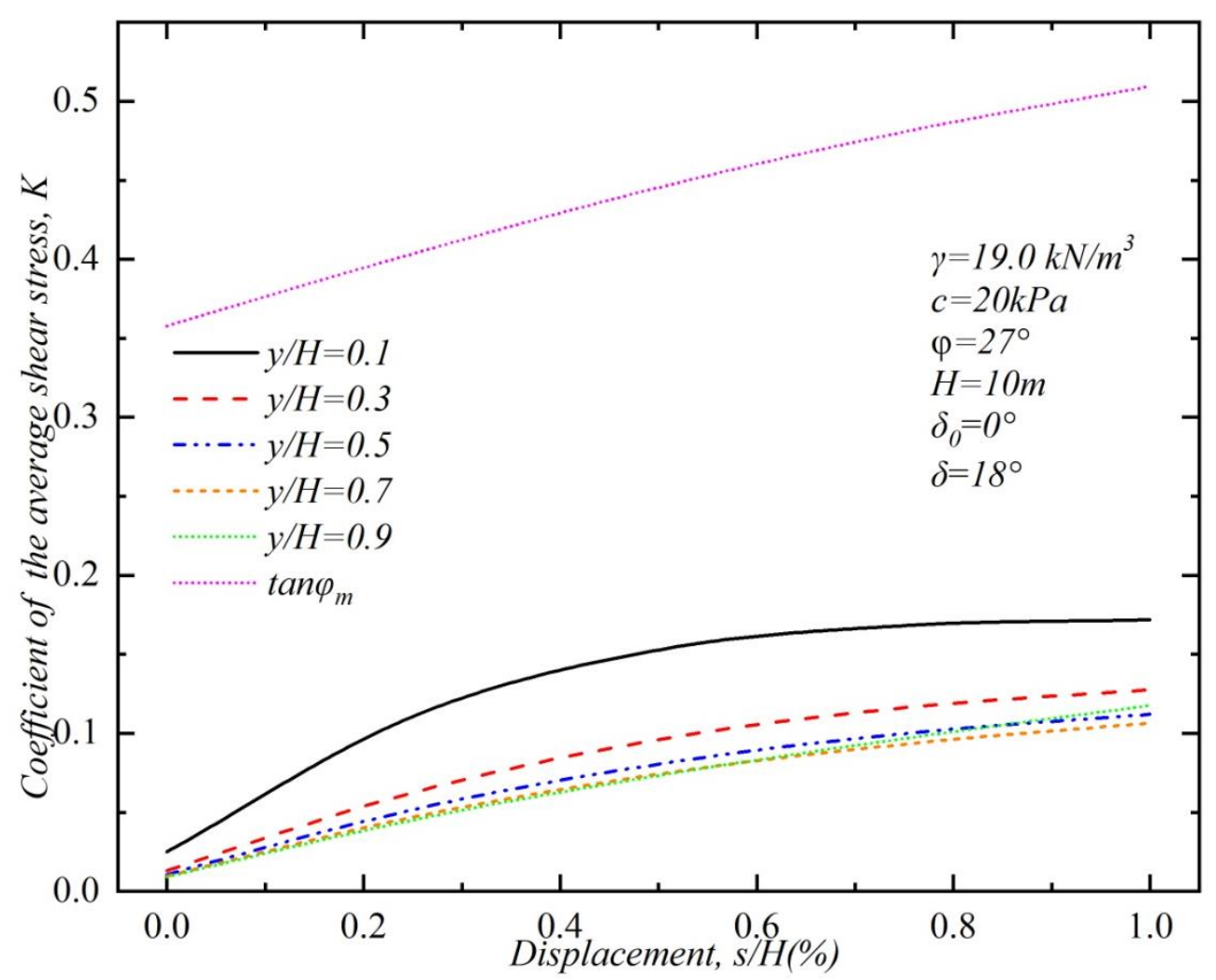

684 Fig. 15 Change in $K$ with different depth and displacement 


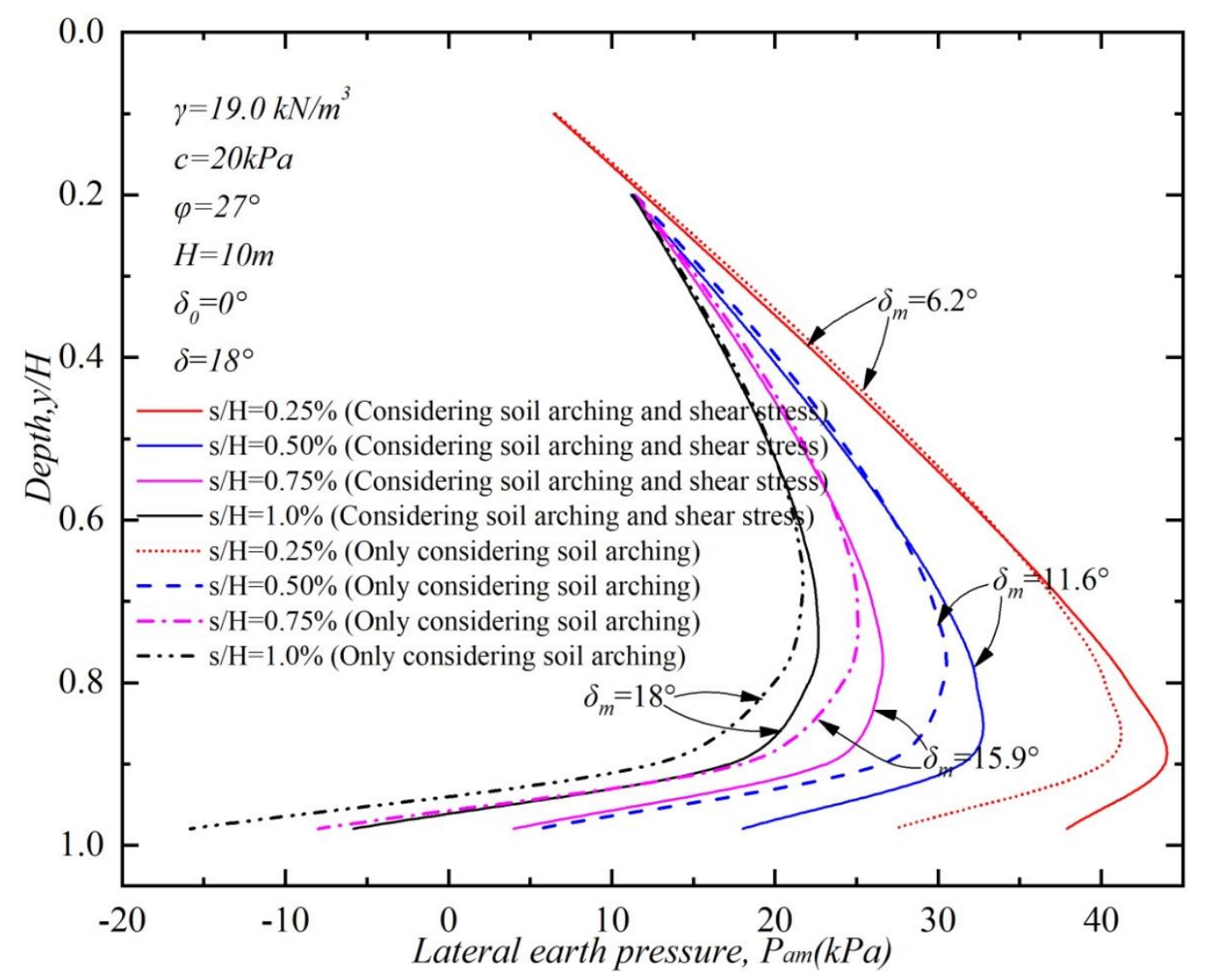

686 Fig. 16 Change of the lateral earth pressure distribution considering arching effect and shear stress or only arching effect 


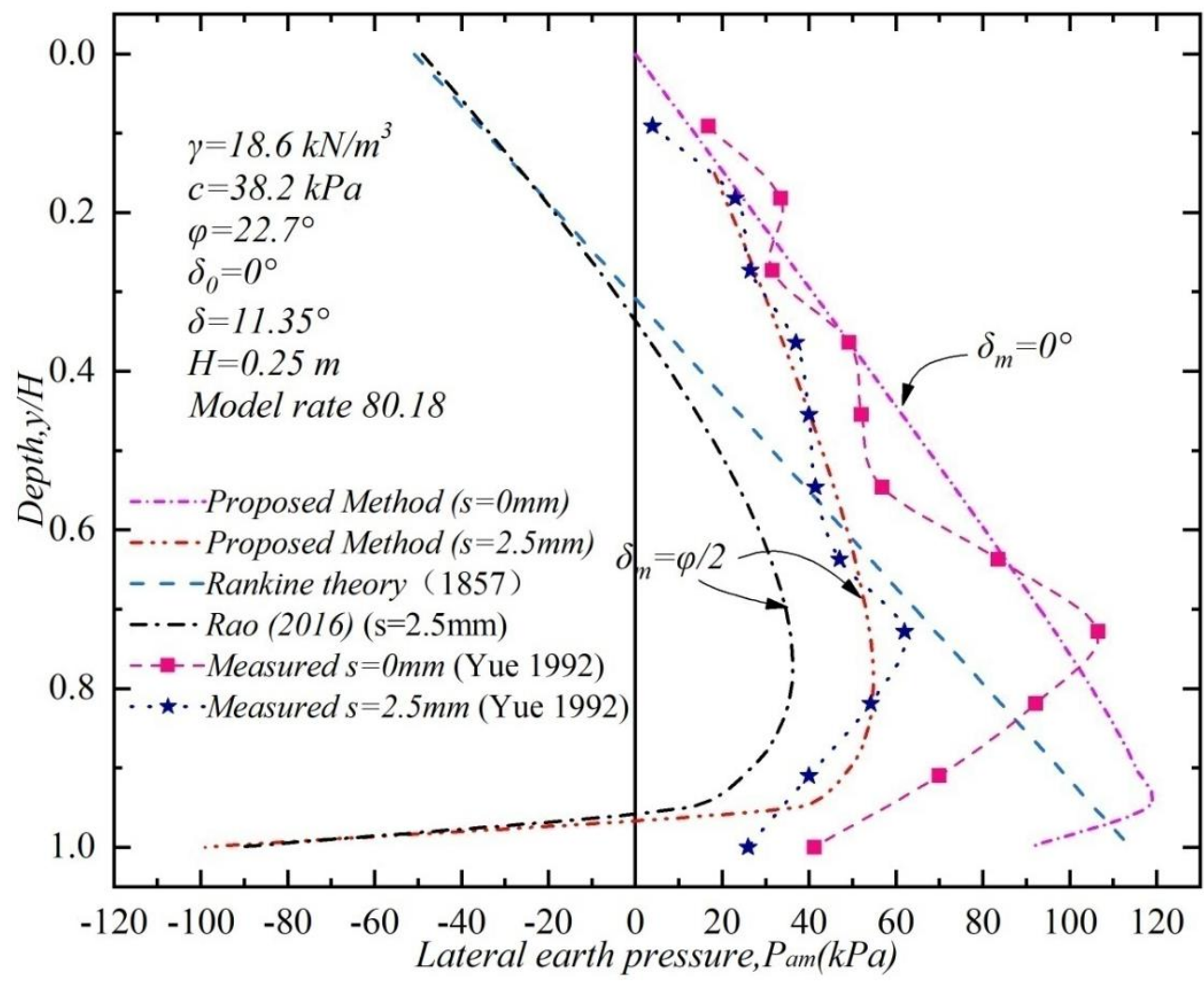

Fig. 17 Comparison between predicted and experimental values obtained about lateral earth pressure 690 in cohesive-frictional soil 


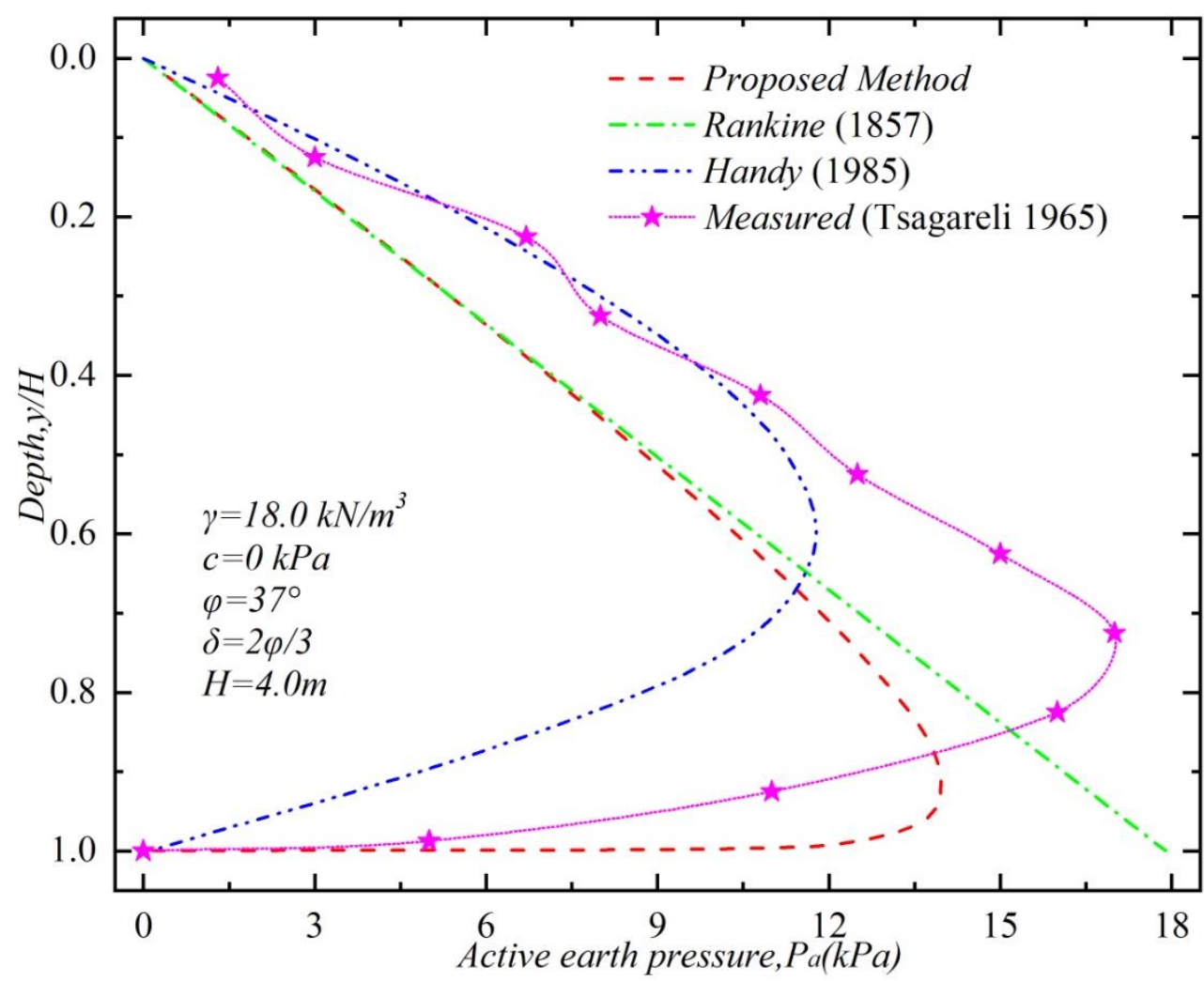

693

Fig. 18 Comparison between predicted and experimental values obtained about active earth pressure in cohesionless soil 
Figures

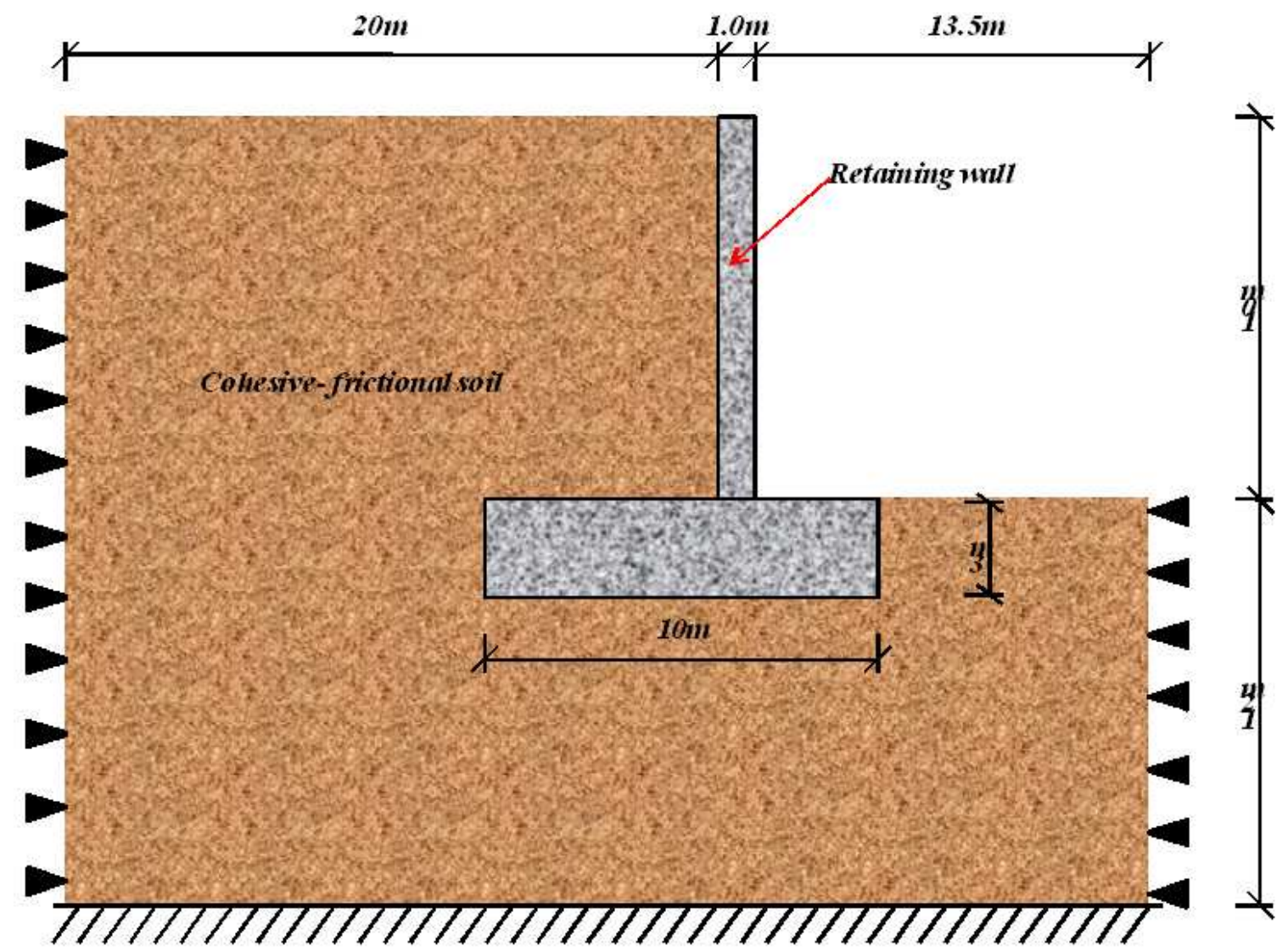

Figure 1

Finite element analytical model for the lateral earth pressure 


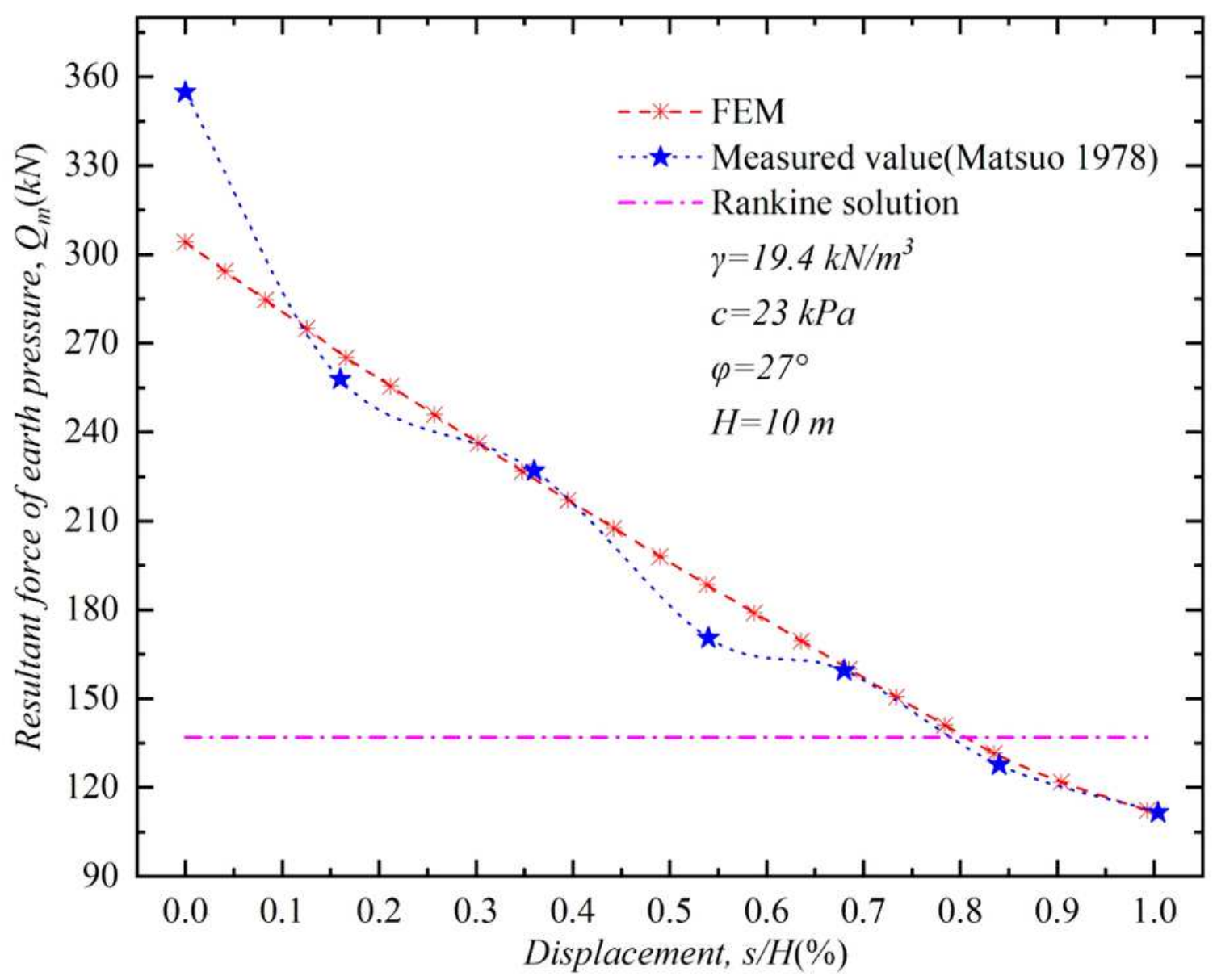

Figure 2

Variation of resultant force of the lateral earth pressure with the wall movement 


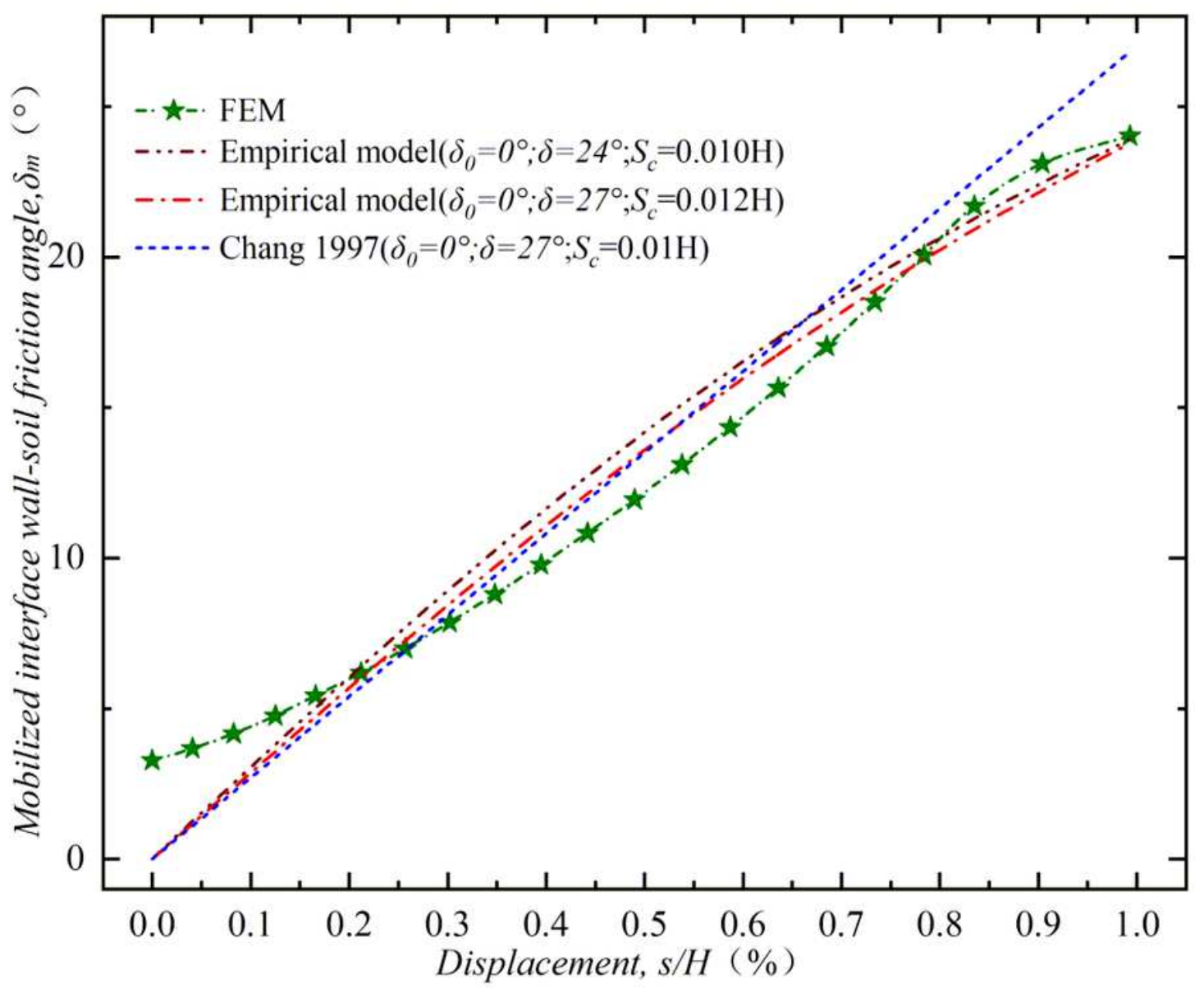

Figure 3

Comparison of the mobilized soil-wall interface friction angles under different methods and conditions 


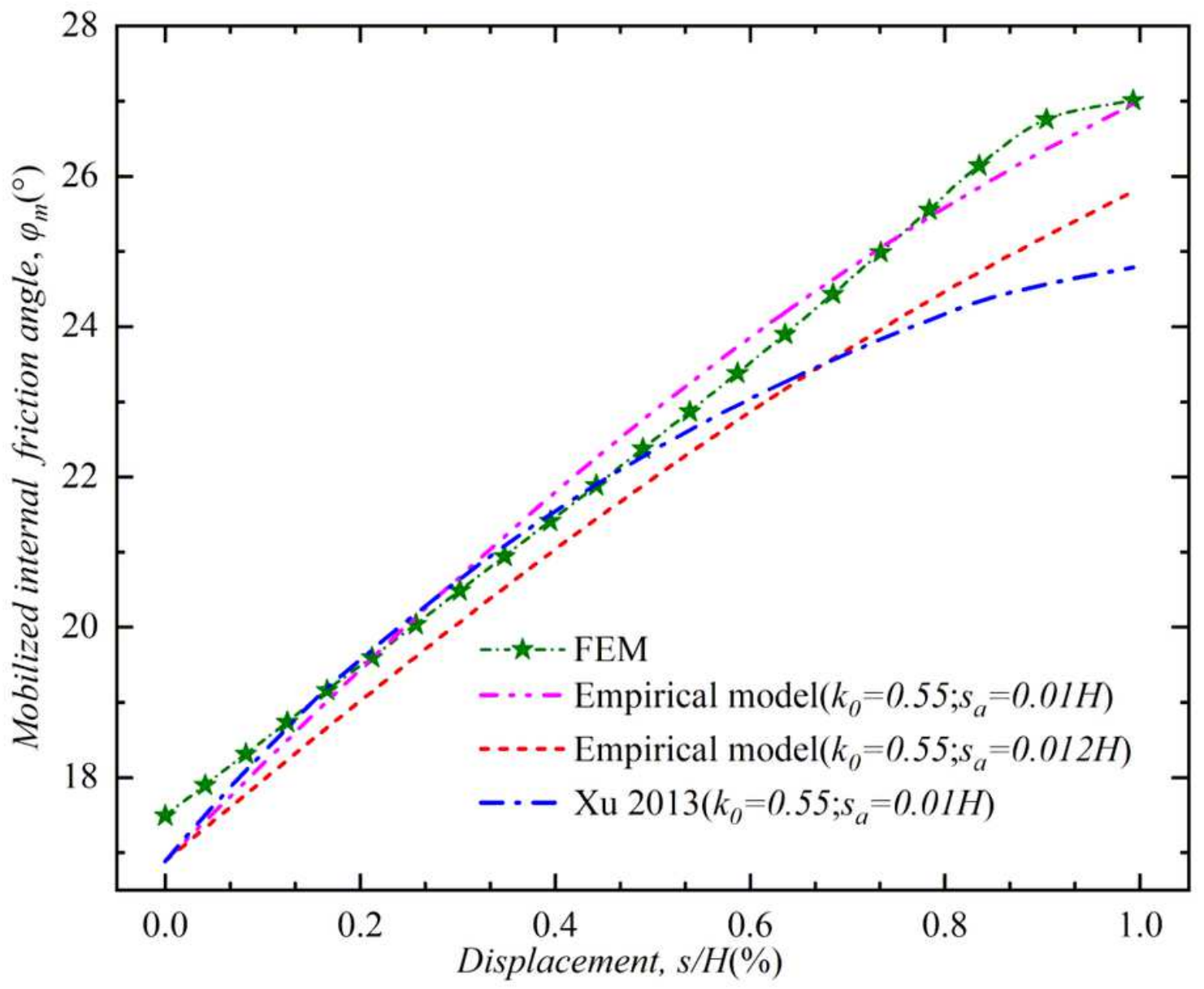

Figure 4

Comparison of the mobilized internal friction angles under different methods and conditions 


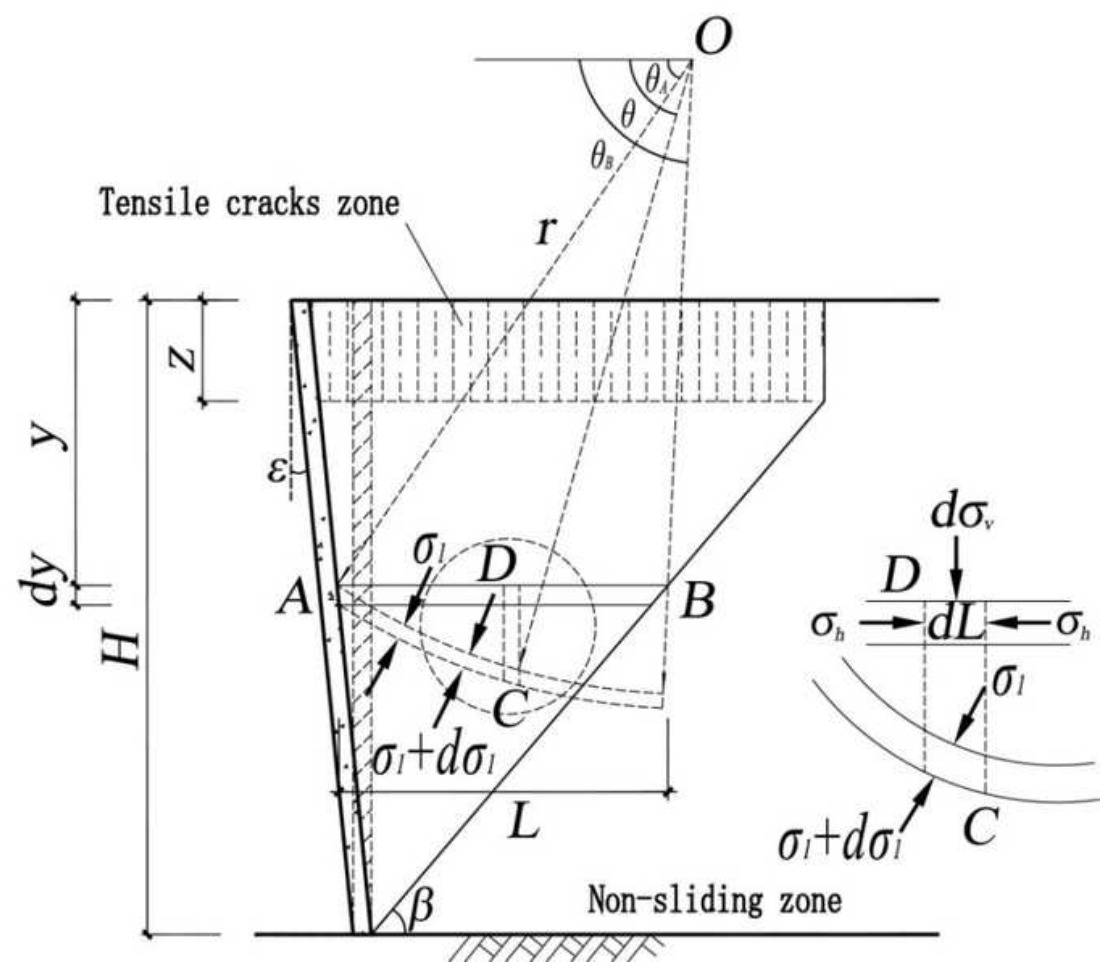

\section{Figure 5}

Trajectory of the minor principal stress in the differential element of the sliding wedge

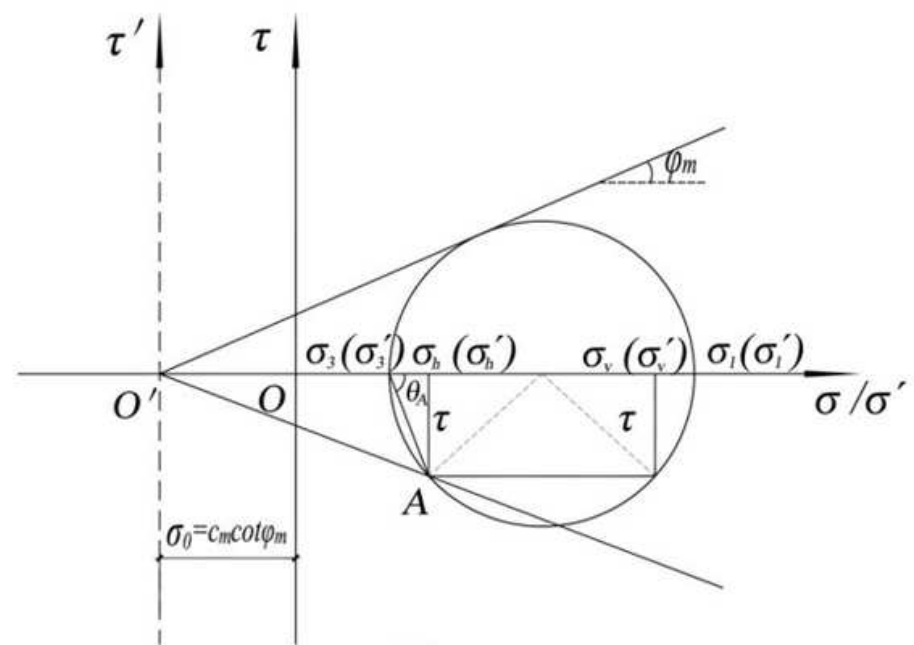

(a)

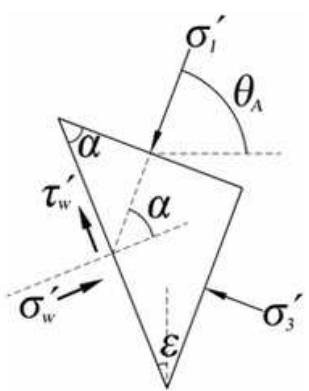

A point

(b)

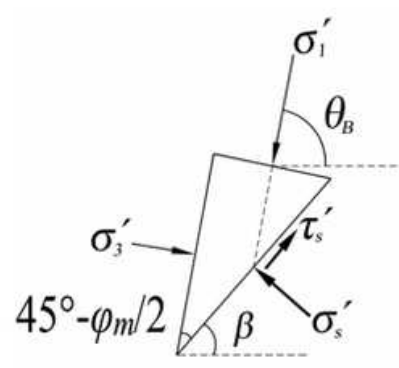

B point

(c)

\section{Figure 6}

Mohr's circle representation of the stresses on point A (a) and the stress analysis in the sliding wedge (b, c) 


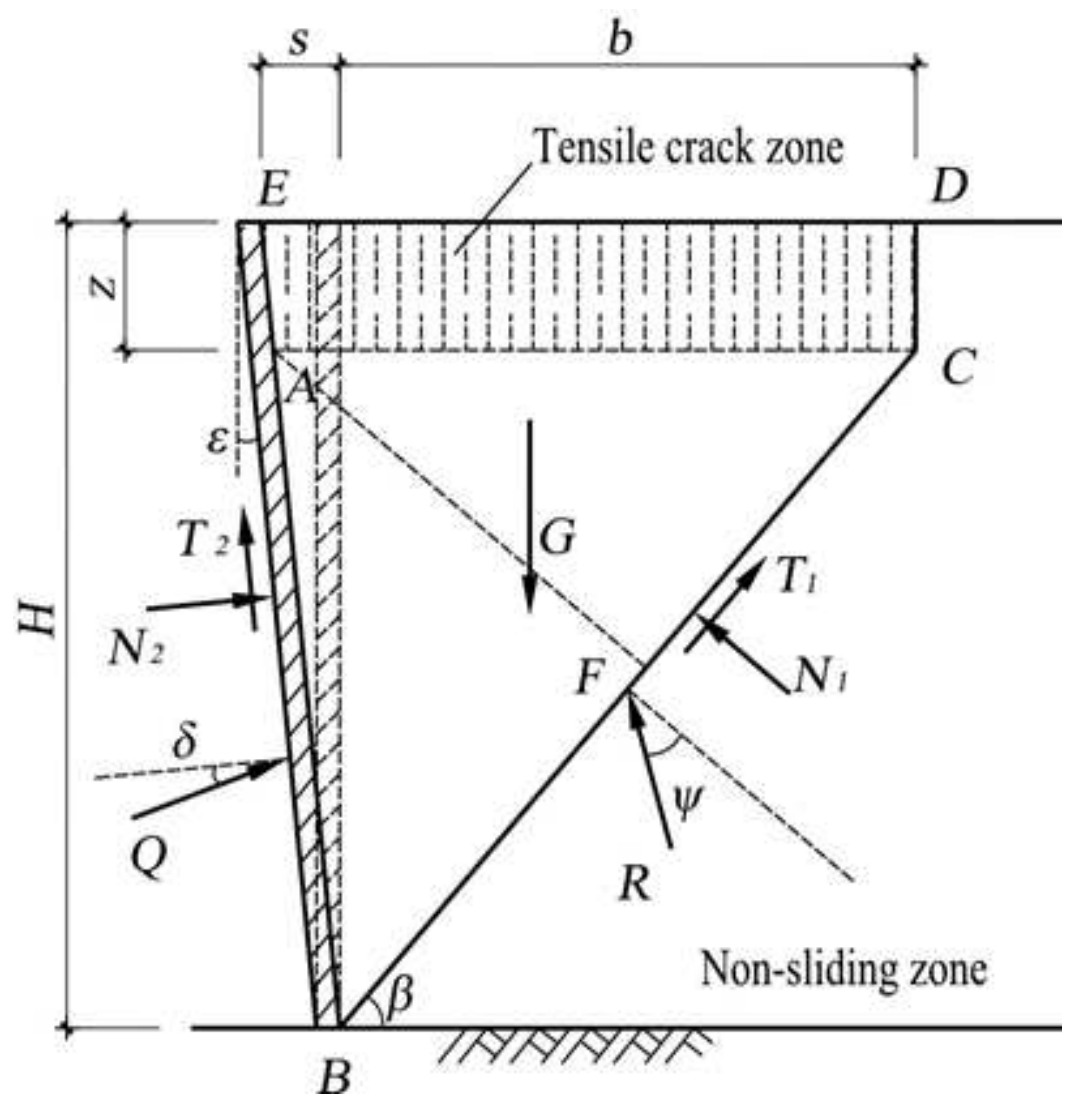

Figure 7

Static equilibrium of the soil-wall system

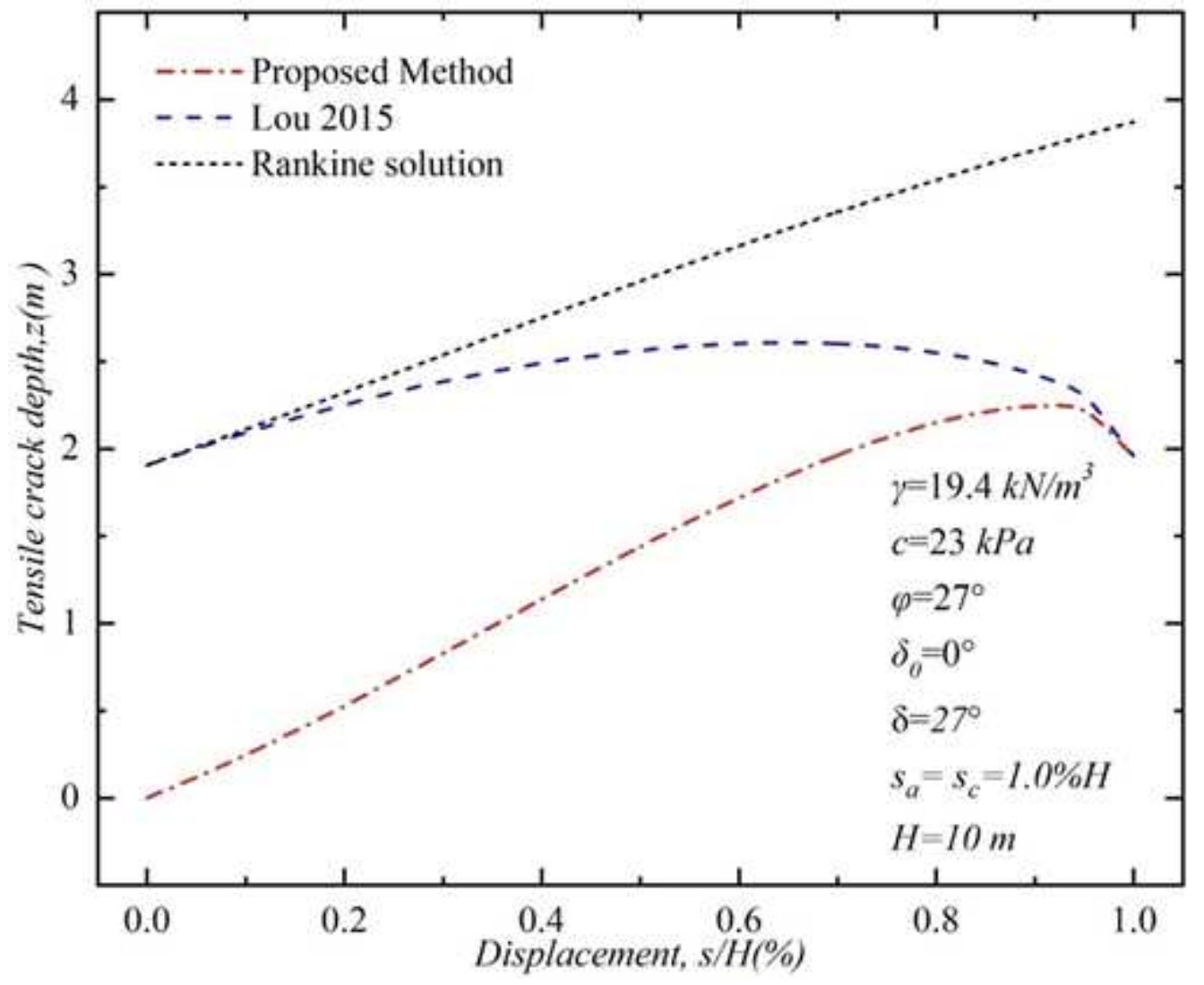


Figure 8

Comparison between the proposed method and other theoretical methods for tension cracks

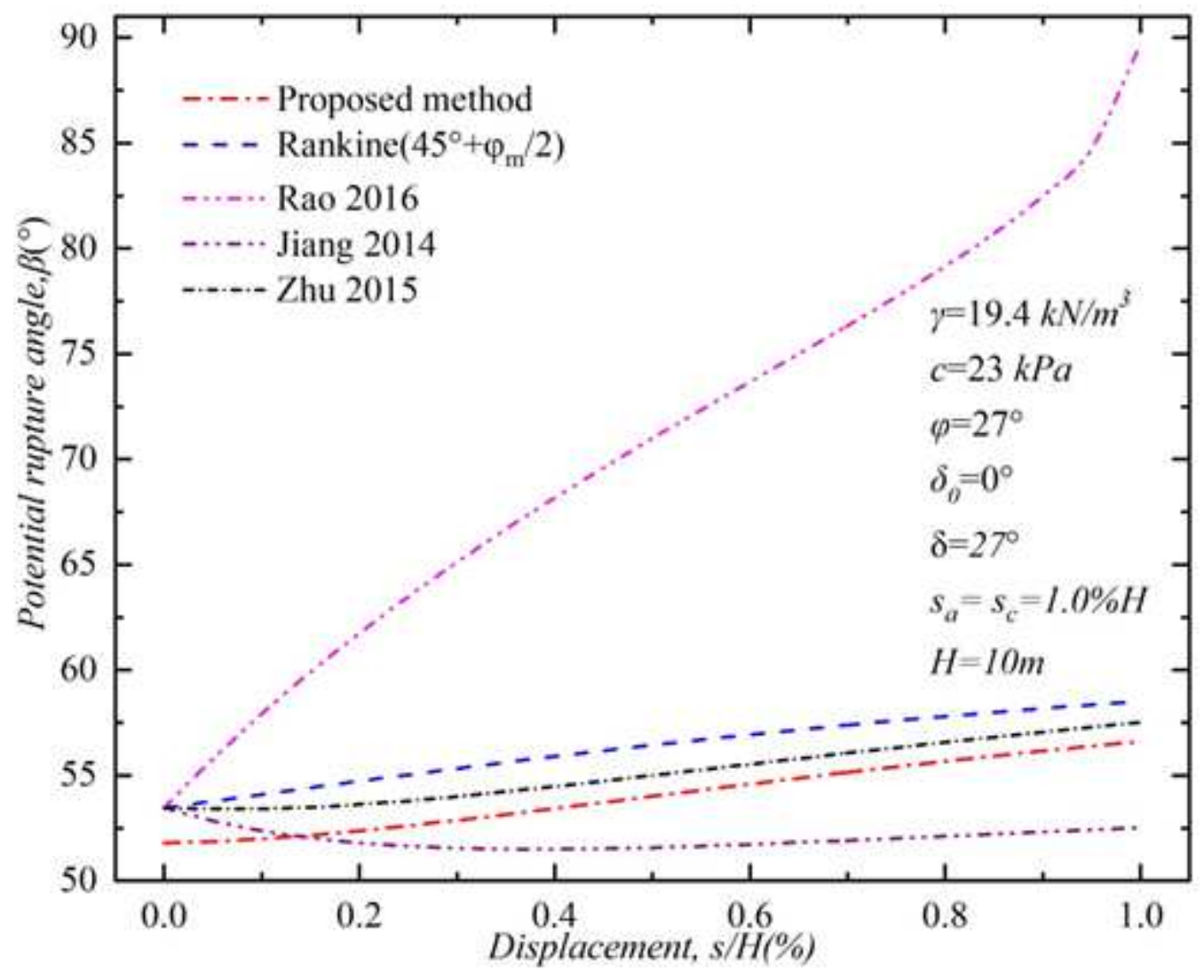

Figure 9

Comparison between the proposed method and other theoretical methods on the potential rupture angle 


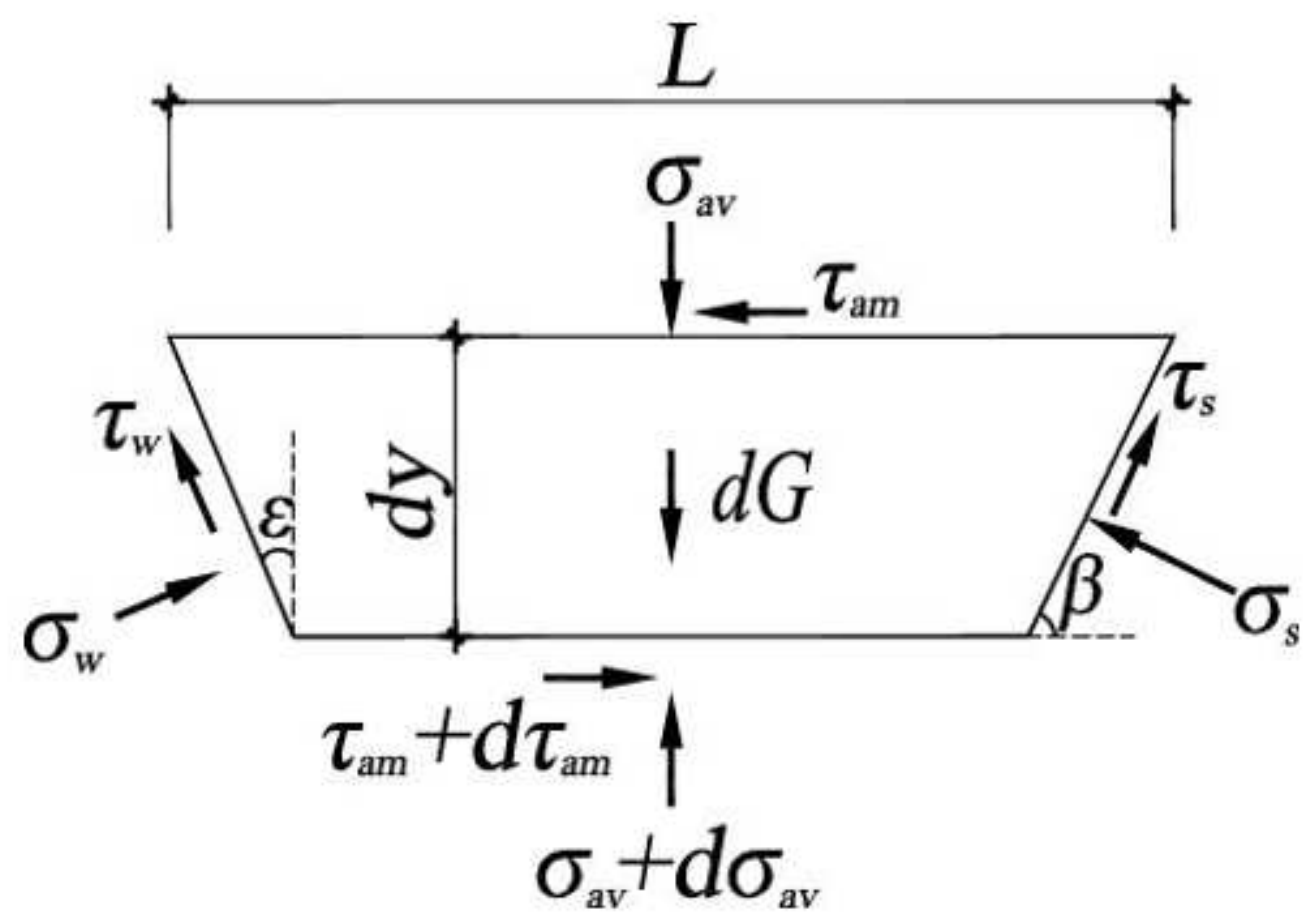

Figure 10

Forces acted on the AB trapezoidal layer element

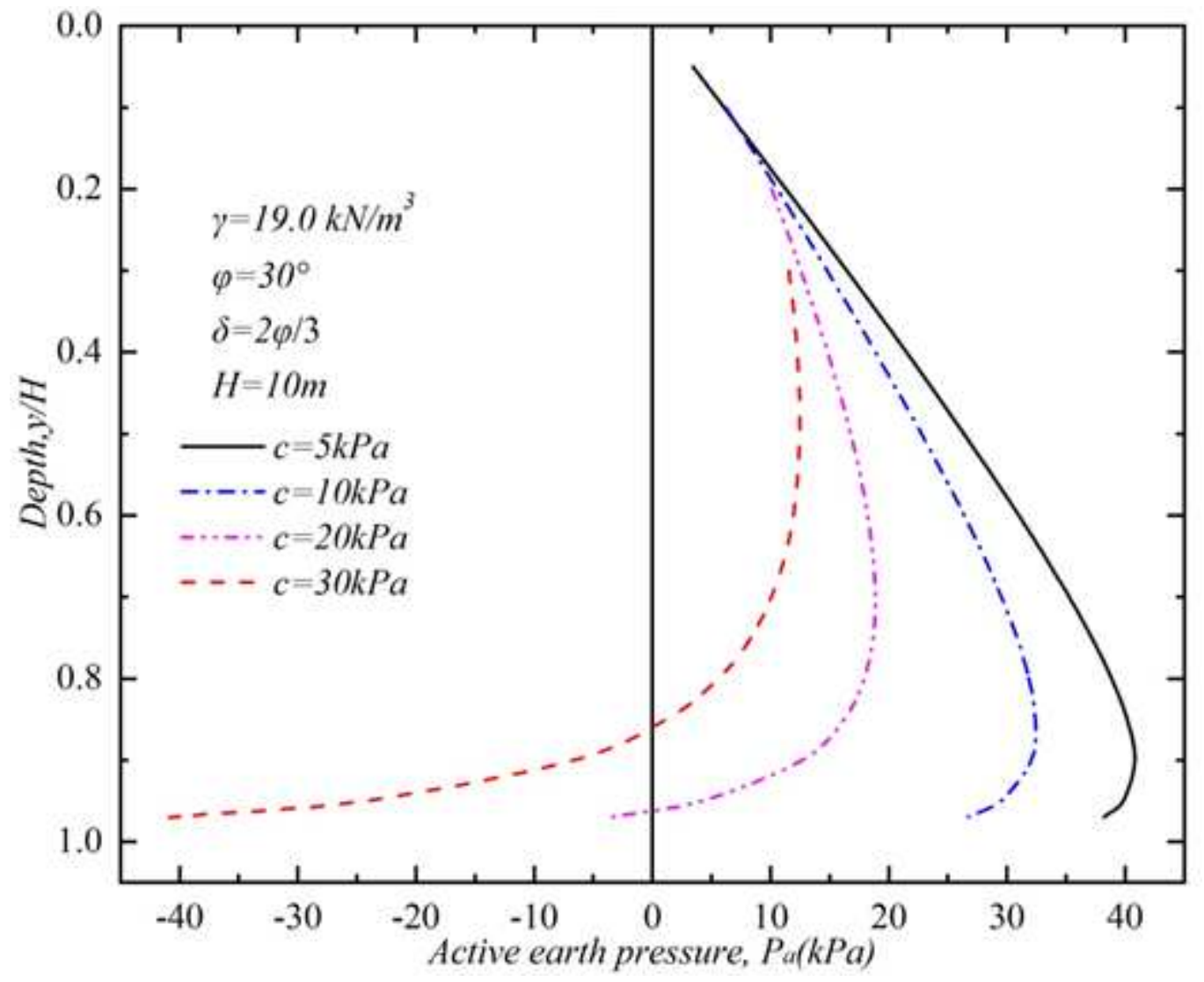

Figure 11 
Change of active earth pressure distribution with different cohesion

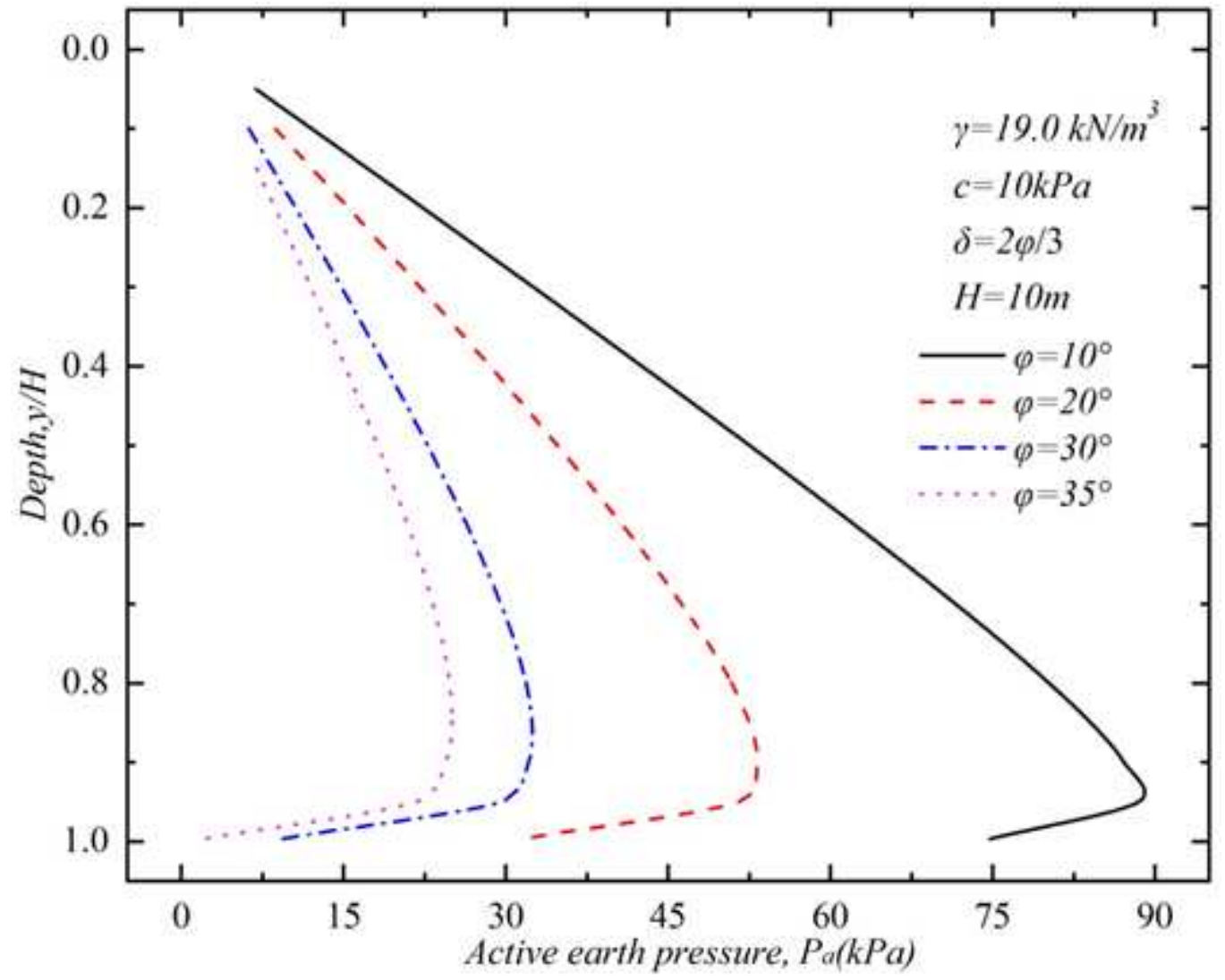

Figure 12

Change of active earth pressure distribution with different friction angles

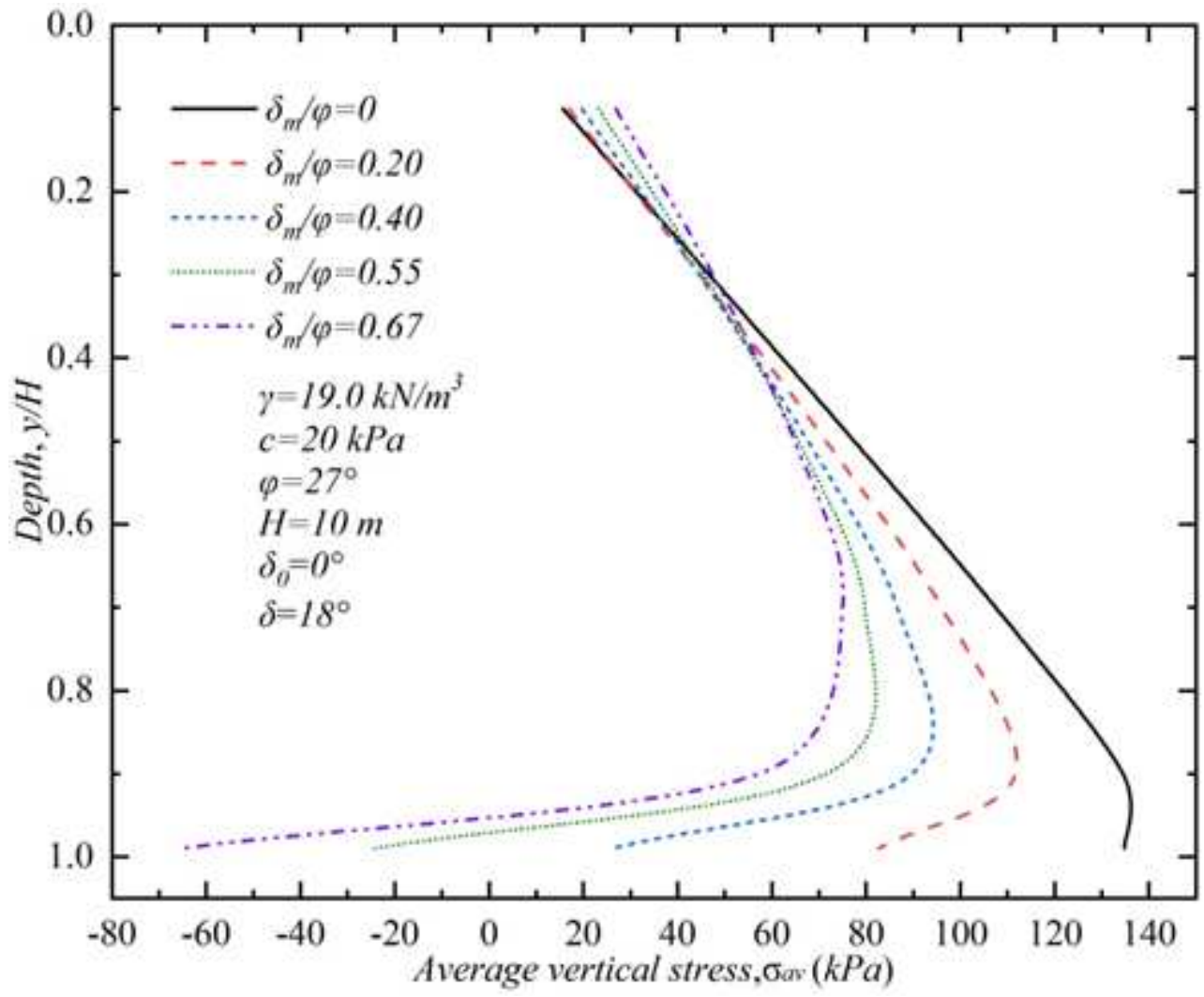


Figure 13

Variations of the average vertical stress with different depth and soil-wall interface friction angle

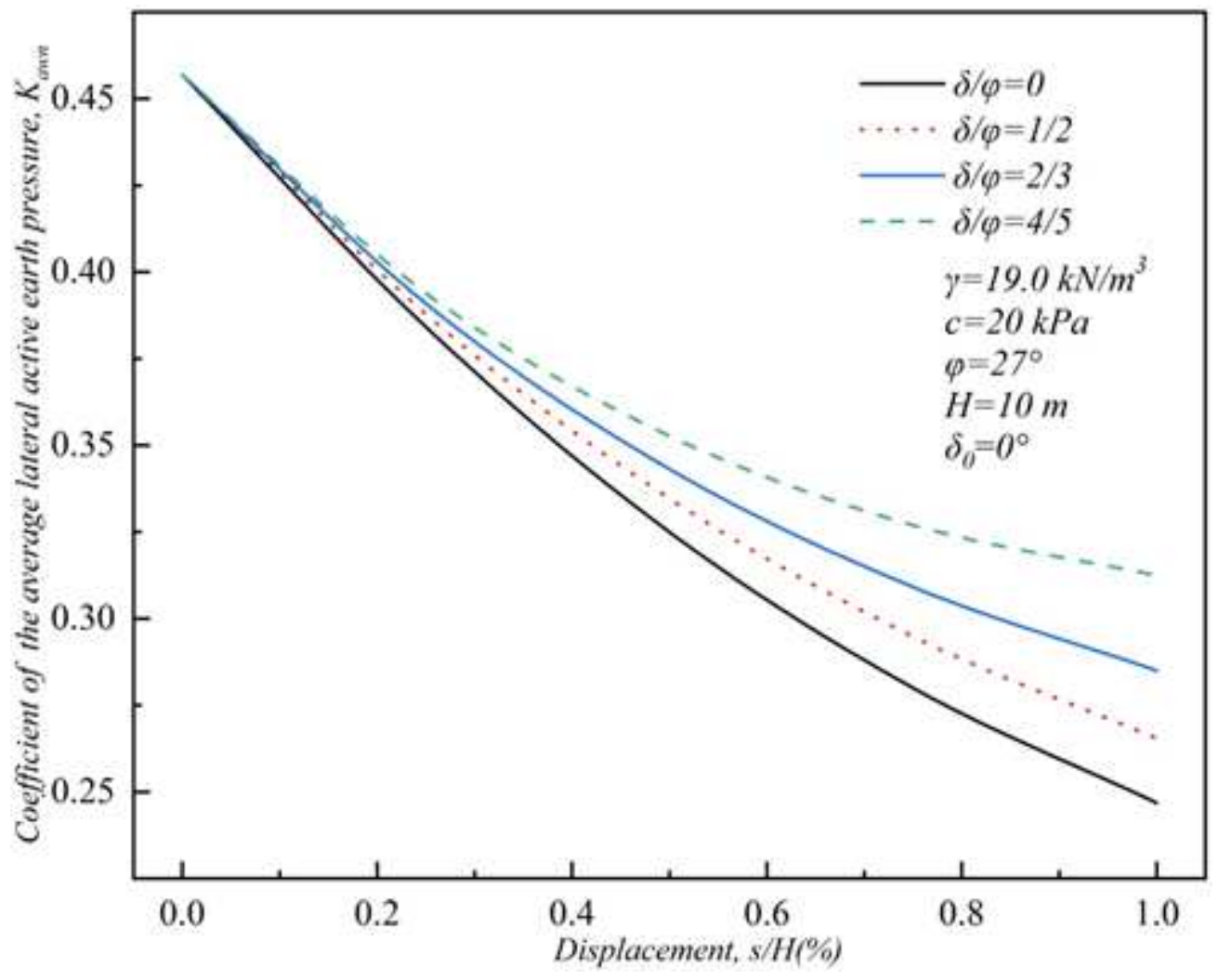

Figure 14

Change in Kawn with different critical soil-wall interface friction angle and displacement

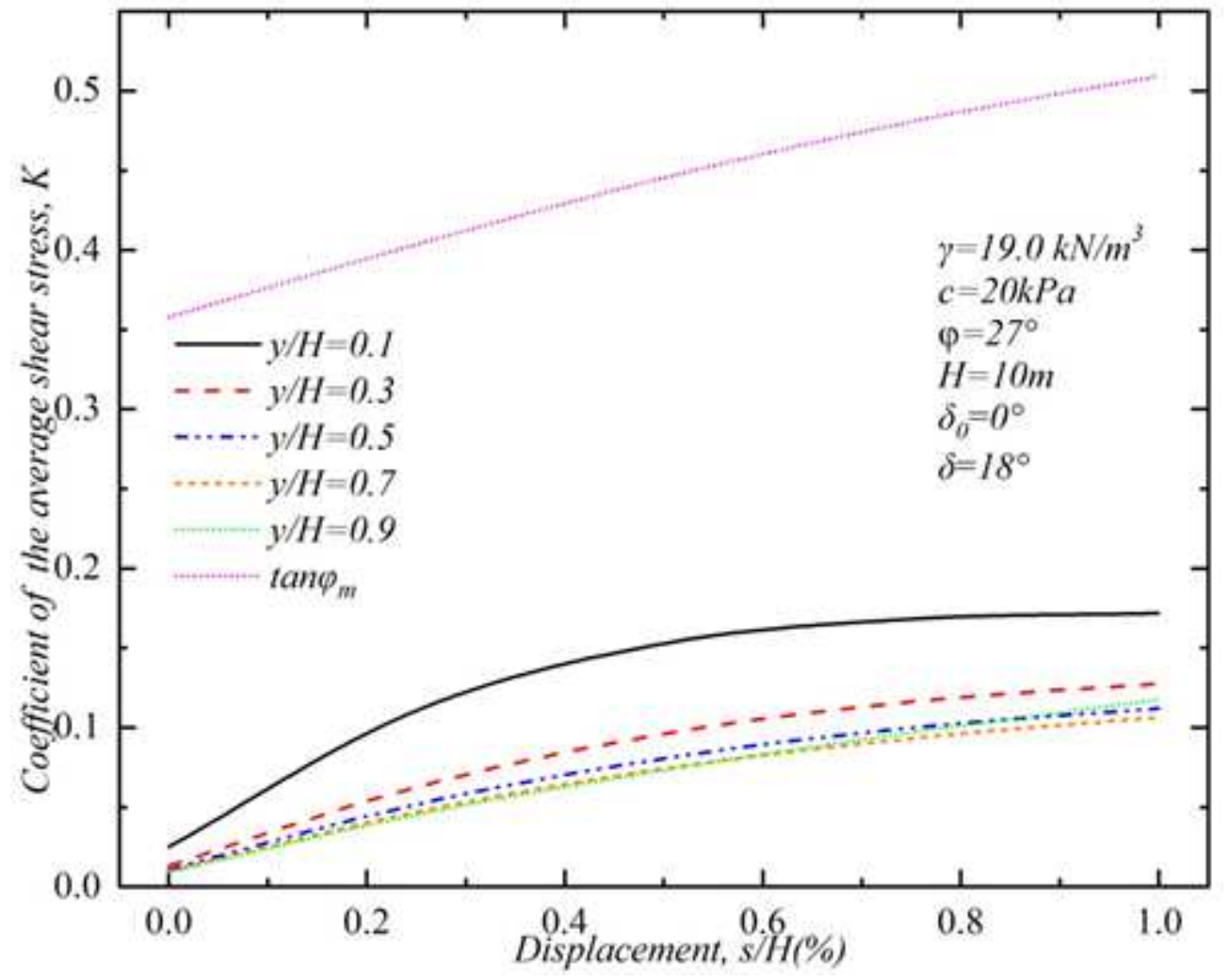


Figure 15

Change in $\mathrm{K}$ with different depth and displacement

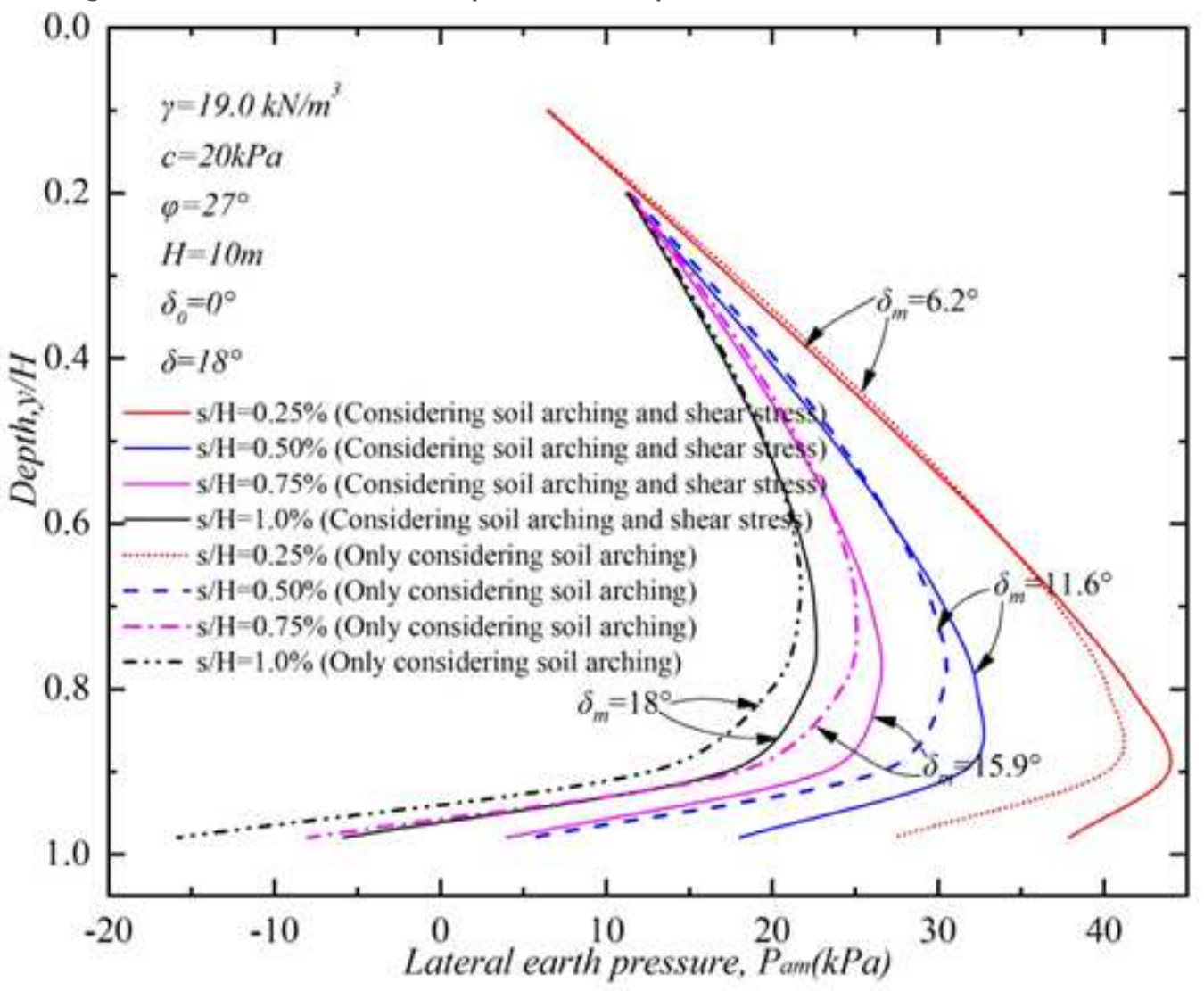

Figure 16

Change of the lateral earth pressure distribution considering arching effect and shear stress or only arching effect 


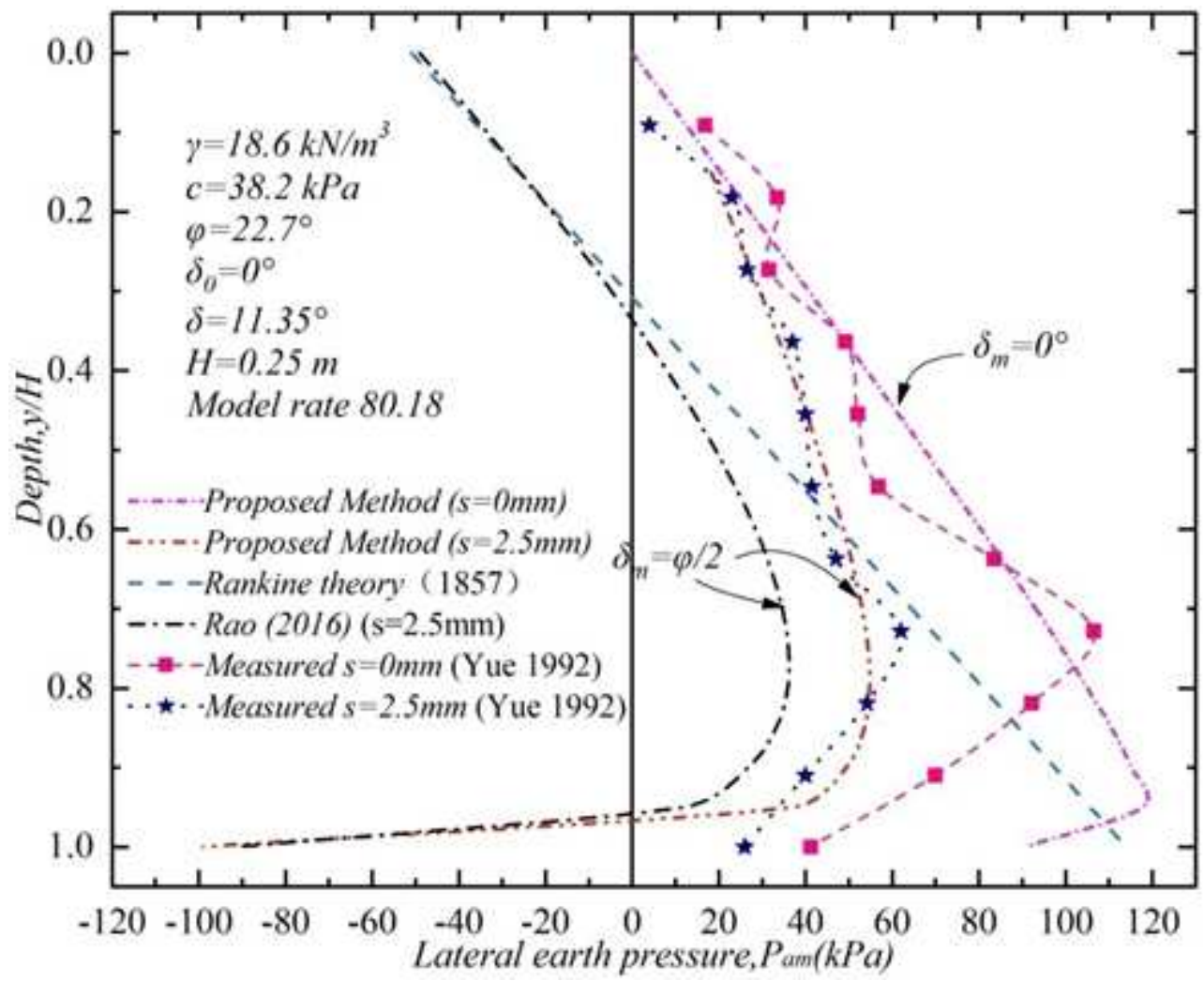

Figure 17

Comparison between predicted and experimental values obtained about lateral earth pressure in cohesive-frictional soil

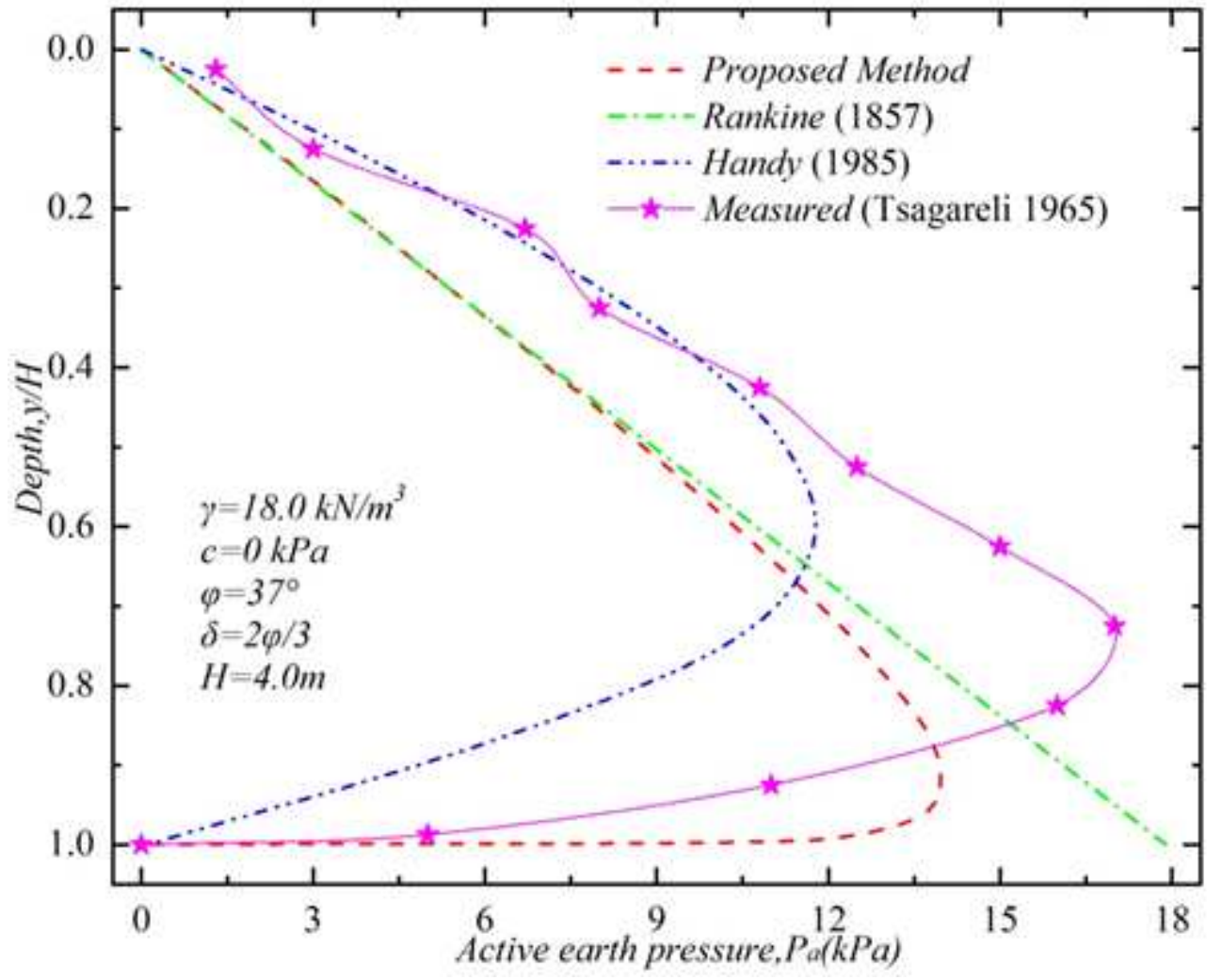

Figure 18 
Comparison between predicted and experimental values obtained about active earth pressure in cohesionless soil 